\title{
New species and combinations of some New Zealand agarics belonging to Clitopilus, Lyophyllum, Gerhardtia, Clitocybe, Hydnangium, Mycena, Rhodocollybia and Gerronema
}

\section{Cooper $\mathbf{J A}^{\mathbf{1}}$}

${ }^{1}$ Landcare Research, PO Box 69040, Lincoln 7640, New Zealand

Cooper JA 2014 - New species and combinations of some New Zealand agarics belonging to Clitopilus, Lyophyllum, Gerhardtia, Clitocybe, Hydnangium, Mycena, Rhodocollybia and Gerronema. Mycosphere 5(2), 263-288, Doi 10.5943/mycosphere/5/2/2

\begin{abstract}
A number of newly described species, new combinations and new records of New Zealand agaric fungi are introduced together with diagnostic descriptions, phylogenetic position and additional notes. The new species are Clitopilus kamaka, Lyophyllum moncalvoanum, Gerhardtia pseudosaponacea, Clitocybe brunneocaperata, Hydnangium kanuka. The new combinations are Rhodocollybia purpurata and Gerronema waikanaensis. Mycena stevensoniae is a nom. nov. for Crinipellis roseola, and the new record for New Zealand is Lyophyllum atratum.
\end{abstract}

Key words - agarics - clitopilus - collybia - fungi - gerhardtia - gerronema - hydnangium lyophyllum - mycena - new species - New Zealand - rhodocollybia

\section{Introduction}

This report of a number of new species and new combinations of New Zealand agaric fungi arises from documenting and sequencing material collected primarily during the annual fungal foray of the Fungal Network of New Zealand society (FUNNZ). The re-combinations of Rhodocollybia purpurata and Gerrronema waikanaensis, and the nom. nov. Mycena stevensoniae share a similar story: many published descriptions of New Zealand agarics before the 1980s are brief and the authors often assigned species to genera with a different modern interpretation. It is sometimes difficult to reconcile recent collections against these older names; especially where images of a representative range of fresh material are absent. The appropriate application of some older names can be re-established only through the combination of revising type collections, together with adequately documented and representative recent collections, and associated diagnostic sequencing. The Fungal Foray in particular provides a significant human resource for collecting and documenting material for such comparative studies.

\section{Materials \& Methods}

\section{Morphological protocols}

Colours were matched with standard plates (Kornerup \& Wanscher 1981). Spores dimensions are stated as the mean \pm 1.5 standard deviations of a stated number of measurements, thus covering $86 \%$ of an assumed normal distribution model. Fresh or dried material was examined 
and routinely mounted in $10 \% \mathrm{KOH}$ or Melzer's reagent. Material was hand-sectioned. Some micrographs were obtained under DIC illumination. Measurements were always obtained without DIC optics and with an extended objective iris in order to maximise boundary contrast. All material is deposited in the New Zealand Fungal and Plant Disease Collection (PDD). A number of cultures are deposited in the International Collection for Microorganisms from Plants (ICMP). Additional images, field notes and annotations associated with all collection and cultures are available online through the Systematic Collection Data (SCD) website of Landcare Research, New Zealand.

\section{Phylogenetic protocols}

DNA extraction and ITS/LSU sequencing followed the protocols outlined in Cooper \& Leonard (2011). Similar and relevant sequences used in cited publications were downloaded from GenBank (Supplementary material). General sequence management was done in Geneious (Drummond et al. 2011). Sequence alignment was carried out using MAFFT within Geneious (Katoh 2002) using the L-INS-i algorithm. A maximum likelihood analysis was executed using PhyML within Geneious (Guindon \& Gascuel 2003), with 100 bootstrap runs, the GTR substitution model and other default parameters. Nodes with relevant bootstrap proportions are shown. All sequences produced during this work have been submitted to GenBank.

\section{Results}

\section{New species}

Clitopilus kamaka J.A. Cooper, sp. nov.

Fig. 1

IndexFungorum IF550154

Holotype - PDD 96106

Etymology - kamaka, from Māori for rock, indicating the predominantly saxicolous habit of this fungus.

Diagnosis - The pleurotoid group of Clitopilus includes, at least, C. scyphoides f. reductus, C. rhodophyllus, C. hobsonii, C. hobsonii var. chilensis, C. daamsii, C. rhodotrama, C. cystidiatus, C. passeckerianus, C. fasciculatus, C. incrustatus, C. incrustatus var. macrospora, C. argentinus, C. pinsitus, C. venososulcatus and two unnamed species (Horak 2008). C. kamaka differs from all of them in the combination of smooth hyaline spores when fresh, small but obscured lateral stipe, and predominantly saxicolous habitat.

Macromorphology - pileus white, discolouring tan with age, 1-6 $\mathrm{mm}$ in diameter, crepidotoid/conchoids in shape. Pileus loosely tomentose when young, becoming felty and weakly radially sulcate with age. Lamellae white becoming slightly pink on drying. Lamellulae present and irregular. Primordia with a minute central stipe, becoming eccentrically attached with growth. Stipe eccentric to lateral, maximum size $0.2 \times 0.7 \mathrm{~mm}$, obscured at maturity as an indistinct, tomentose point of attachment.

Micromorphology - basidiospores hyaline, inamyloid, ellipsoid to oblong, $8.1 \pm 0.8 \times 4.1 \pm$ $0.3 \mu \mathrm{m}, \mathrm{Q}=2 \pm 0.2, \mathrm{n}=20$. Spores circular in cross-section, thin-walled, and often released as joined tetrads. In dried material some spores collapsing to produce longitudinal ridges but in fresh material appearing smooth in outline. Basidia clavate $25 \times 8 \mu \mathrm{m}, 4$-spored, with sterigma to $3 \mu \mathrm{m}$, without a basal-clamp. Pleurocystidia and cheilocystidia absent. Trama sometimes with rhomboidal crystals. Pileipellis a loose cutis of unclamped interwoven hyphae to $5 \mu \mathrm{m}$ in diameter, without encrusted pigment. Terminal elements cylindrical to irregular.

Habitat - basidiomata singly or clustered on well-rotted wood, soil, buried twigs, and rock surfaces. Algal growth present on adjacent substrate in all examined material.

Known distribution and conservation status - endemic in New Zealand. Known only from a few sites in the Port Hills and Bank Peninsula region of Mid-Canterbury. The same sites contain Macrocystidia reducta, a readily identified secotioid fungus which also appears to be restricted to this region; although Clitopilus kamaka is easily overlooked. 


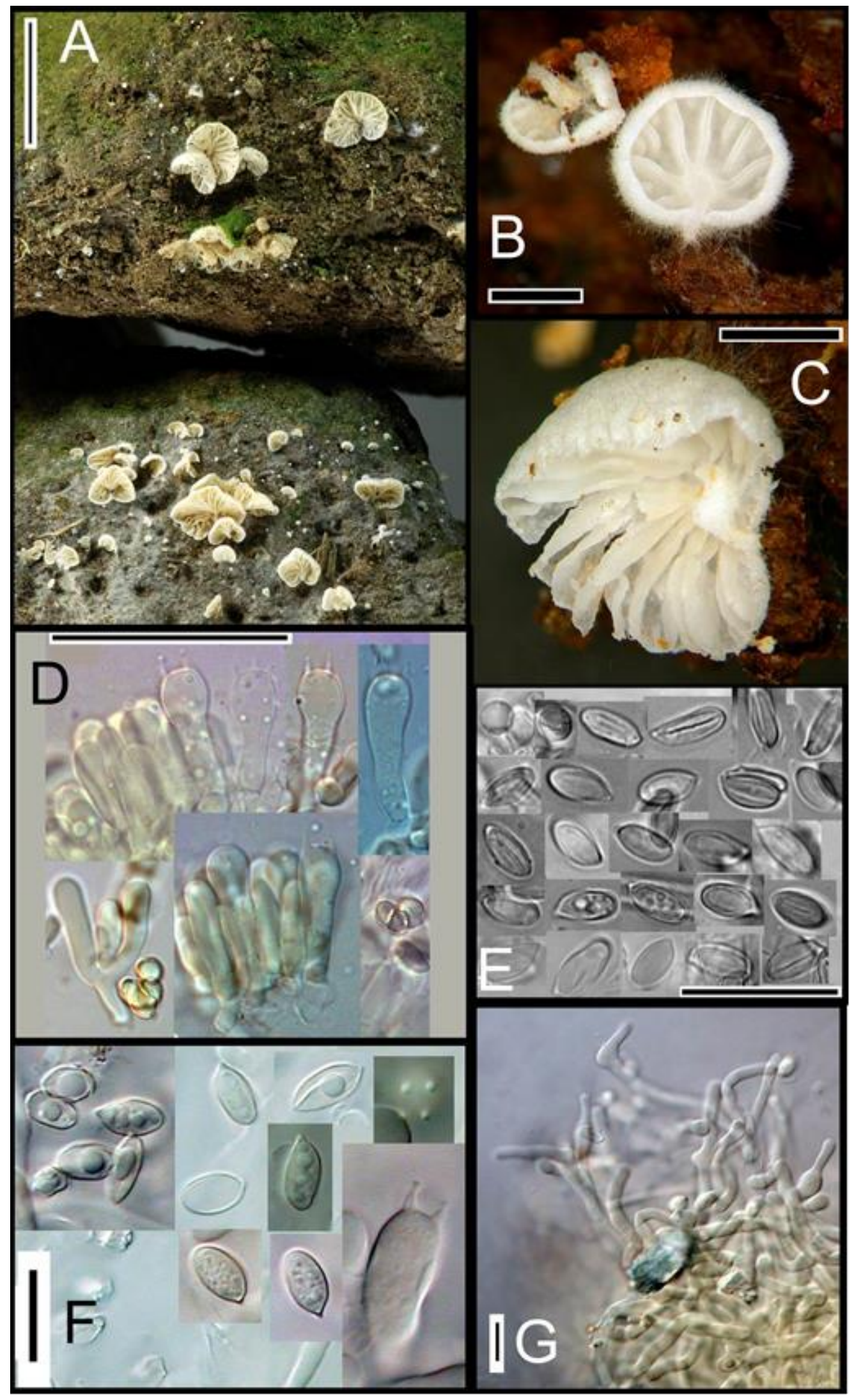

Fig. 1 - Clitopilus kamaka. A PDD 96106 Saxicolous habitat with associated alga, bar $=10 \mathrm{~mm}$. B PDD 87290 detail showing evanescent stipe on immature basidiomata, bar $=1 \mathrm{~mm}$. C PDD 87321 mature basidiomata, bar $=1 \mathrm{~mm}$. D basidia, in Melzer's reagent, bar $=40 \mu \mathrm{m}$. E PDD 96106 spores from dried material, in Melzer's reagent, spores collapsing along weak ridges, top left polar view, bar $=20 \mu \mathrm{m}$. F PDD 87367 basidia and spores from fresh material, in Melzer's reagent, bar $=10$ $\mu \mathrm{m} . \mathrm{G}$ pileipellis hyphae, bar $=10 \mu \mathrm{m}$. 
Material examined - New Zealand, Mid-Canterbury, Little River, Okuti Reserve, on soil, 7th Jan 2007, J.A. Cooper, JAC10199 (PDD 87290). New Zealand, Mid-Canterbury, Port Hills, Kennedy's Bush, on rotten log, 11th Feb 2007, J.A. Cooper, JAC10231 (PDD 87321, culture ICMP 16972). New Zealand, Mid-Canterbury, Port Hills, Kennedy's Bush, on rock with alga, 25th Dec, 2007, J.A. Cooper, JAC10278 (PDD 87367). New Zealand, Mid-Canterbury, Port Hills, Omahu Bush, on rock with alga,15th Feb 2010, JAC11246 (PDD 95725). New Zealand, Mid-Canterbury, Port Hills, Watling Track, on rock with alga, 11th January, 2010, J.A. Cooper, JAC11684 (PDD 96106 Holotype).

GenBank - KJ461903 (PDD96106. ITS)

Notes - Horak (2008) described, but did not name, two pleurotoid Clitopilus spcecies in his revision of New Zealand Entolomataceae. C. kamaka most resembles Horak's C. sp. [PDD88169] in being strigose at the point of attachment. However in that species the spores are clearly ridged in polar view and broader.

A phylogram of the ITS region of similar sequences in GenBank (Fig. 2) indicates the species is closely related to C. giovanellae. Moreno et al 2007 established the new section Omphalodei of Clitopilus for $C$. giovanellae on the basis of its hyaline, smooth spores and phylogenetic position. C. kamaka belongs in the Omphalodei but differs in being eccentrically and transiently-stiped whereas $C$. giovanellae is centrally-stiped and omphaloid.

C. kamaka and $C$. giovanellae are related to species which have been demonstrated to produce the broad-spectrum antibiotic pleuromutilin (Hartley et al. 2009) originally derived from Pleurotus mutilus ( $\equiv$ Omphalina mutila). The phylogram indicates that a number of names in this group are currently being applied to a number of different species. Watling 1989, comments on the historic confusion of two members of the group, $O$. mutila and $C$. scyphoides. Further work is required to establish correct use of existing names in this group.

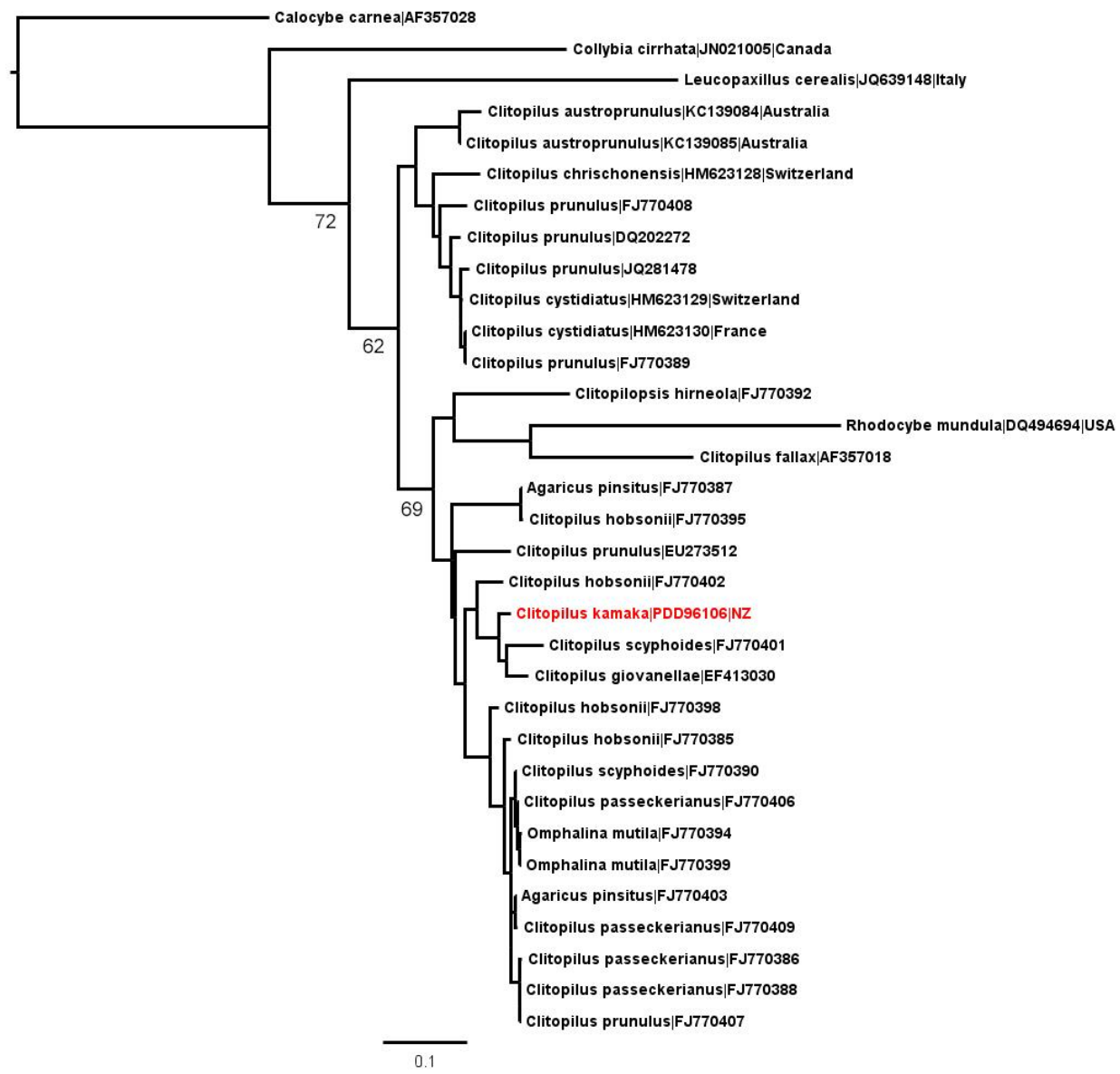

Fig. 2 - ML ITS phylogram of Clitopilus kamaka with selected related sequences available from GenBank. The tree has been rooted with Calocybe carnea. 


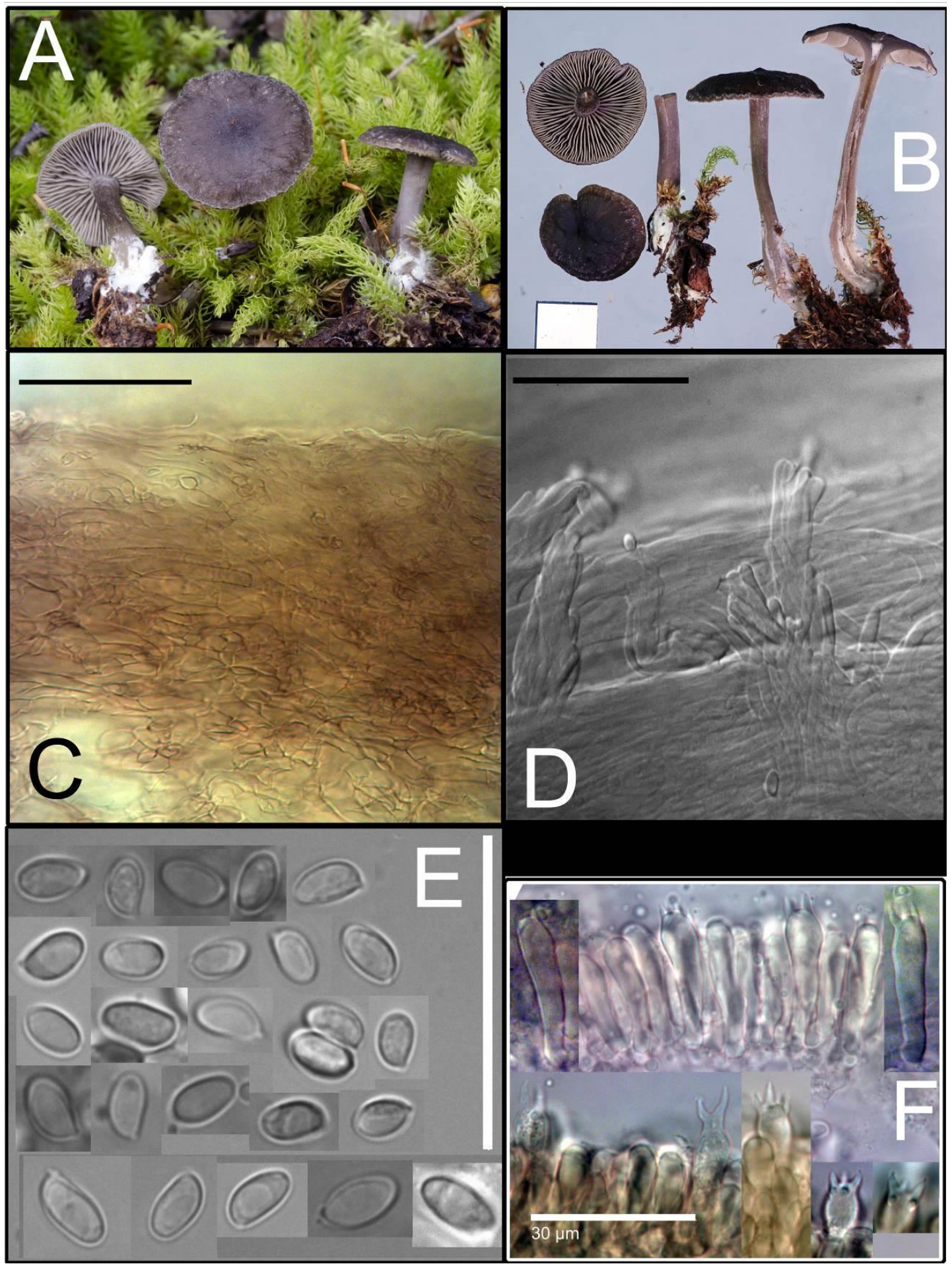

Fig. 3 - Clitocybe brunneocaperata. A PDD 96472 habitat. B bar $=10 \mathrm{~mm}$. C vertical pileipellis section, in Melzer's reagent, bar $=50 \mu \mathrm{m}$. D caulocystidia, bar $=50 \mu \mathrm{m}$. E Basidiospores, scale $=$ $30 \mu \mathrm{m}$. F basidia, scale $=30 \mu \mathrm{m}$.

Etymology - brunneocaperata, referring to the brown wrinkled pileus.

Diagnosis - Clitocybe brunneocaperata differs from other New Zealand species of Clitocybe by the adnate lamellae, dark brown rugulose pileus and non-hygrophanous basidiomata. 


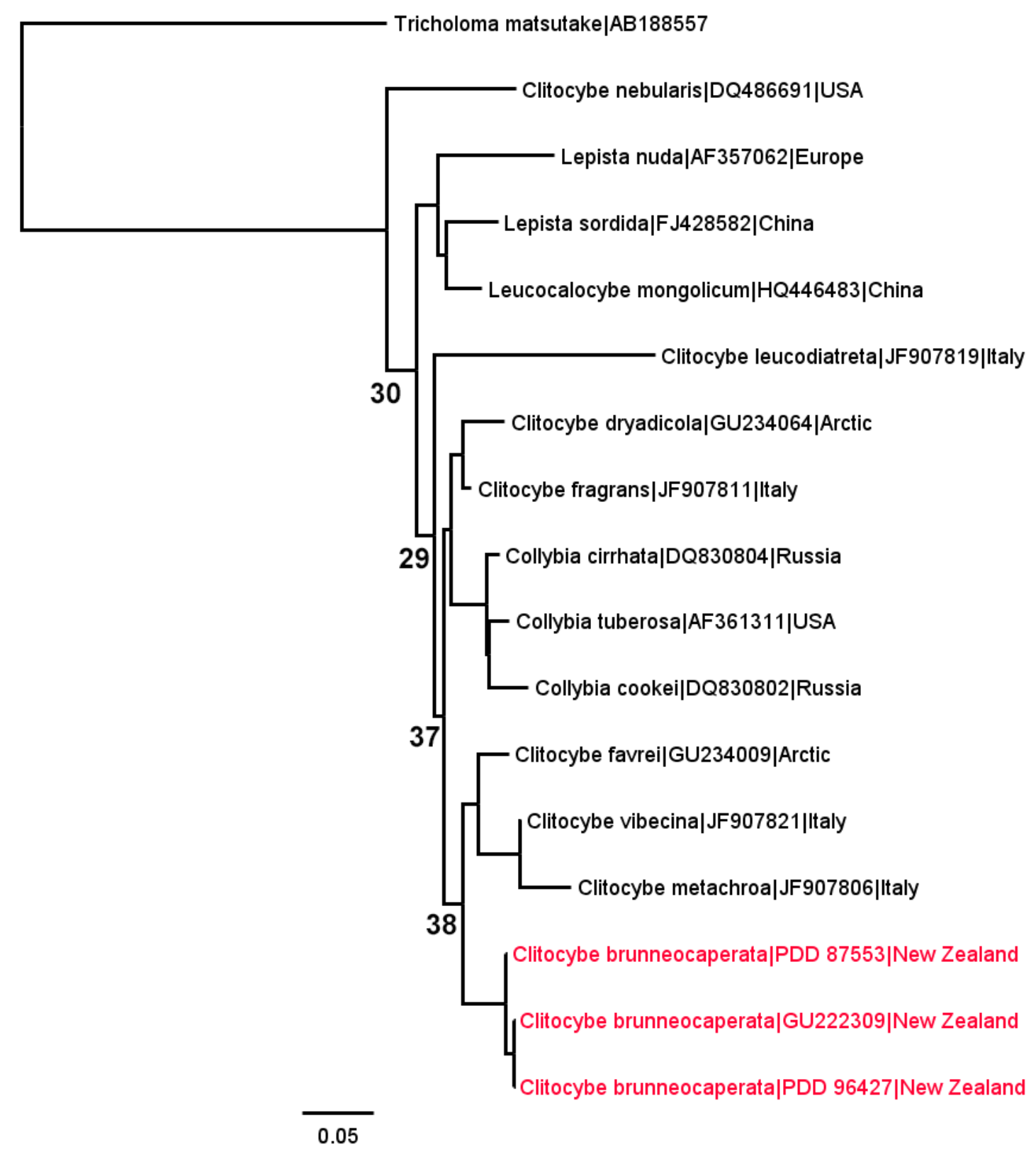

Fig. 4 - ML ITS phylogram of Clitocybe brunneocaperata and related sequences available in GenBank. The tree has been rooted with Tricholoma matsutake.

Macromorphology - pileus $10-20 \mathrm{~mm}$ diameter, convex to applanate in shape and radially rugulose. Pileus colour brown-vinaceous (10F8) to mouse-grey (10F1), margin striate, uneven. Lamellae attachment adnate. Lamellae colour cream to vinaceous buff (9D3). Lamellae present in a series of three. Stipe cylindrical, to $70 \mathrm{~mm}$ long, and to $3 \mathrm{~mm}$ diameter, swollen towards base to $7 \mathrm{~mm}$ diameter. Stipe concolorous with pileus. Stipe flesh fibrous in texture and concolorous with pileus. Stipe base with white binding hyphae and a poorly formed white/yellow dense mass of hyphae, to $8 \mathrm{~mm}$ diameter. Taste none. Smell faintly rubbery or farinaceous.

Micromorphology - Spores hyaline, oblong, $6.2 \pm 0.9 \times 3.5 \pm 0.4 \mu \mathrm{m}, \mathrm{Q}=1.8 \pm 0.2, \mathrm{n}=25$. Spores with apiculus and slight supra-hilar depression, glassy walled, cyanophilous, inamyloid. Basidia $2 \& 4$-spored, clavate, to $50 \times 6 \mu \mathrm{m}$. Sterigma to $6 \mu \mathrm{m}$ in length. Pileipellis partially gelatinised, consisting of interwoven, hyaline, clamped hyphae. Pileipellis hyphae to $5 \mu \mathrm{m}$ diameter and with extracellular zebroid, pale brown, encrusted pigment. Pileipellis forming a layer $100 \mu \mathrm{m}$ thick, over loose interwoven subpellis. Lamellae trama with gloeoplerous hyphae. Lamellae without cystidia. Stipitipellis with scattered apical caulocystidia in agglutinate fascicles, cylindrical, $50 \times 4 \mu \mathrm{m}$. 
Habitat - singly, in litter in beech (Nothofagus) forest.

Known distribution and conservation status - endemic in New Zealand. Currently with few collections but probably overlooked or confused with other species.

Material examined - New Zealand, Mid Canterbury, Greyney's Shelter, in litter with Nothofagus solandri, 3rd Apr 2012, J.A. Cooper, JAC12375 (PDD 96427 Holotype). New Zealand, Buller, in litter with Nothofagus, 7th May 2006, I. Dickie (PDD 89839). New Zealand, Dunedin, Waipori Falls, Government Track, 12th May 2008, K. Soop, JAC10636 (PDD 87533).

GenBank - KJ461898 (PDD 87533. ITS), KJ461899 (PDD 87533. LSU), KJ461908 (PDD 96427. ITS), KJ461907 (PDD96427. LSU)

Notes - In the field this species could be mistaken for a small Lyophyllum or Tephrocybe, rather than Clitocybe, which generally possesses decurrent lamellae. Members of the Lyophyllaceae demonstrate siderophilous granules in the basidia when treated with iron salts and acetocarmine and $C$. brunneocaperata does not possess them. Sequence data for the ITS and LSU regions place the taxon within a clade containing Clitocybe nebularis, the type species of Clitocybe, and a number of other species (Fig. 4), but with poor support for the internal relationships. The northern hemisphere species $C$. vibecina, and $C$. metachroa share some morphological similarity with $C$. brunneocaperata but have hygrophanous basidiomata without an odour. Collybia tuberosa, the type species of Collybia is also related. Collybia includes relatively few species associated with decaying agarics and often arising from a sclerotium, neither feature associated with $C$. brunneocaperata. Current sequence samples suggest the relationships between Clitocybe, Lepista, Collybia and related taxa require further clarification.

Gerhardtia pseudosaponacea J.A. Cooper \& P. Leonard, sp. nov.

Fig. 5 IndexFungorum IF550156

Holotype - PDD 96650

Etymology - simulating Tricholoma saponaceum, including a weak saponaceous smell.

Diagnosis - differs from existing species of Gerhardtia by the possession of spores with a smooth outline.

Macromorphology - pileus $40-80 \mathrm{~mm}$ in diameter and convex in shape and smooth. Pileus colour straw (3A4) to buff (5B5). Lamellae attachment adnate to emarginate and pale buff in colour. Lamellulae present in a series of two or three. Stipe cylindrical, to $120 \mathrm{~mm}$ long and to 8 $\mathrm{mm}$ in diameter at apex, enlarging towards base to $12 \mathrm{~mm}$, and then sharply attenuated and rooting. Stipe colour white, surface texture innately fibrous. Stipe flesh hollow at the apex otherwise stuffed. Flesh white, unchanging. No taste. Smell weakly saponaceous.

Micromorphology - spore print white. Spores hyaline, subcylindric $5.6 \pm 0.7 \times 2.9 \pm 0.3$ $\mu \mathrm{m}, \mathrm{Q}=2 \pm 0.2, \mathrm{n}=20$. Spores glassy walled, with vacuolar refractive content and apiculus, not cyanophilous. Basidia to $35 \times 7 \mu \mathrm{m}, 4$-spored, and with siderophilous granules. Cheilocystidia cylindrical, to $30 \times 4 \mu \mathrm{m}$. No pleurocystidia. Pileipellis a tightly bound cutis of parallel hyphae with the cuticular layer to $100 \mu \mathrm{m}$ thick, over loose cutis of glassy-walled hyphae. Pileal hyphae to $3.5 \mu \mathrm{m}$ diameter. Pileipellis with occasional gloeoplerous hyphae. Hyphae of context to $8 \mu \mathrm{m}$, unclamped. No tissue reacting with Melzer's reagent.

Habitat - In groups under Nothofagus menziesii.

Known distribution and conservation status - currently known only from a single collection but likely confused with currently undescribed New Zealand species of Tricholoma.

Material examined - New Zealand, Southland, Longwood Road, Martins Hut Track, 8th May 2012, M. Crowe, JAC12535 (PDD96650 Holotype).

GenBank - KJ461911 (PDD 96650. LSU)

Notes - this species is easily mistaken in the field for a member of the contexticutis section of Tricholoma, which includes T. saponaceum, and the New Zealand species T. viridiolivaceum, which is variable in colour and can be similarly pale. Sequence data (Fig. 6) places $G$ pseudosaponacea together with other Gerhardtia species within the Lyophyllaceae. Microscopically this species is distinguished from Tricholoma by the possession of siderophilous 


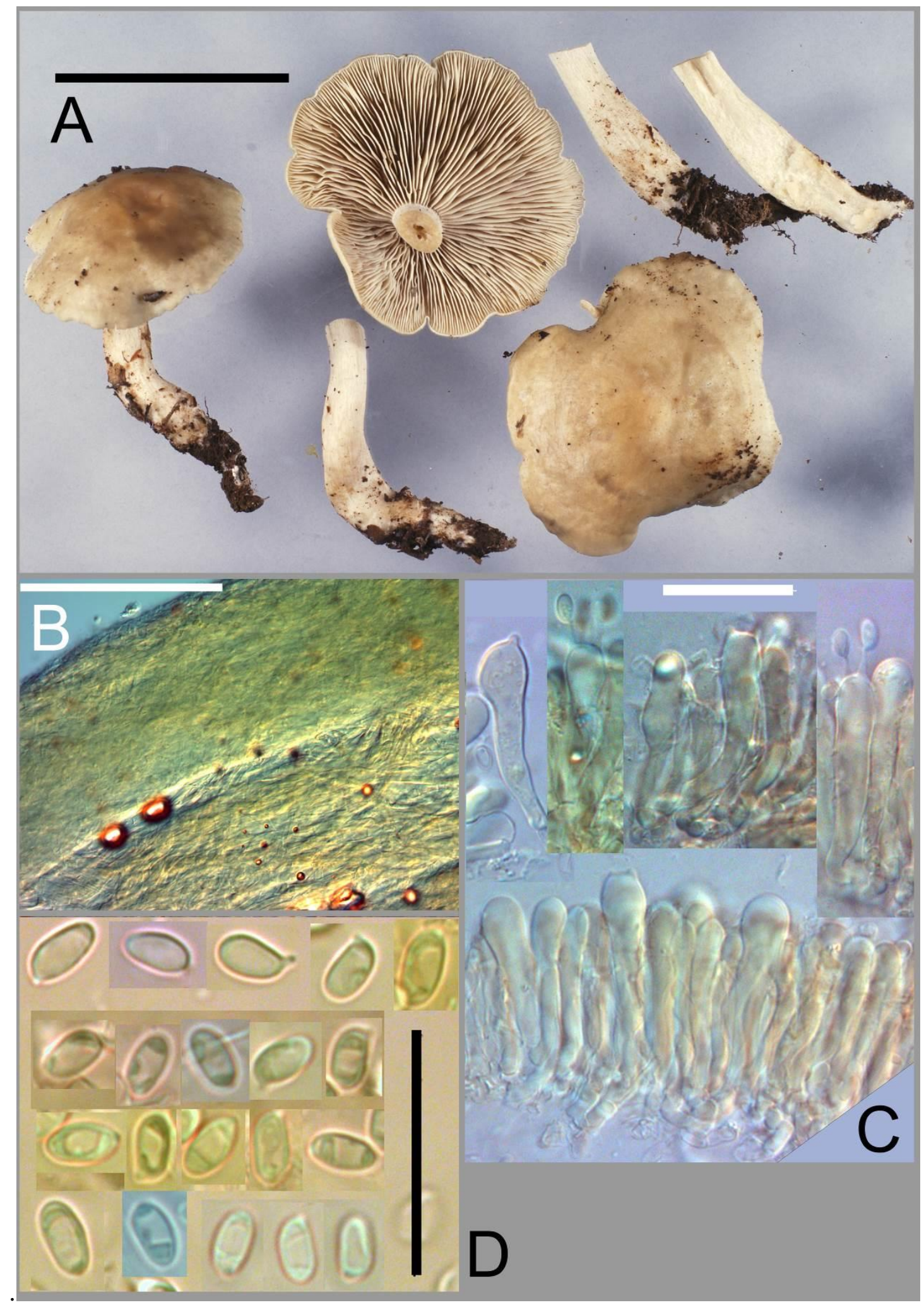

Fig. 5 - Gerhardtia pseudosaponacea PDD 96650. A basidiomata. B section through pileipellis, in Melzer's reagent. C basidia. D spores, in Melzer's reagent.

granules in the basidia, a diagnostic character for the Lyophyllae. Currently described species of Gerhardtia are all distinguished from similar genera by the possession of spores with an irregular outline. G. pseudosaponacea, with smooth spores, introduces a problem in distinguishing this species of Gerhardtia and related Lyophyllaceae using morphological characters. 


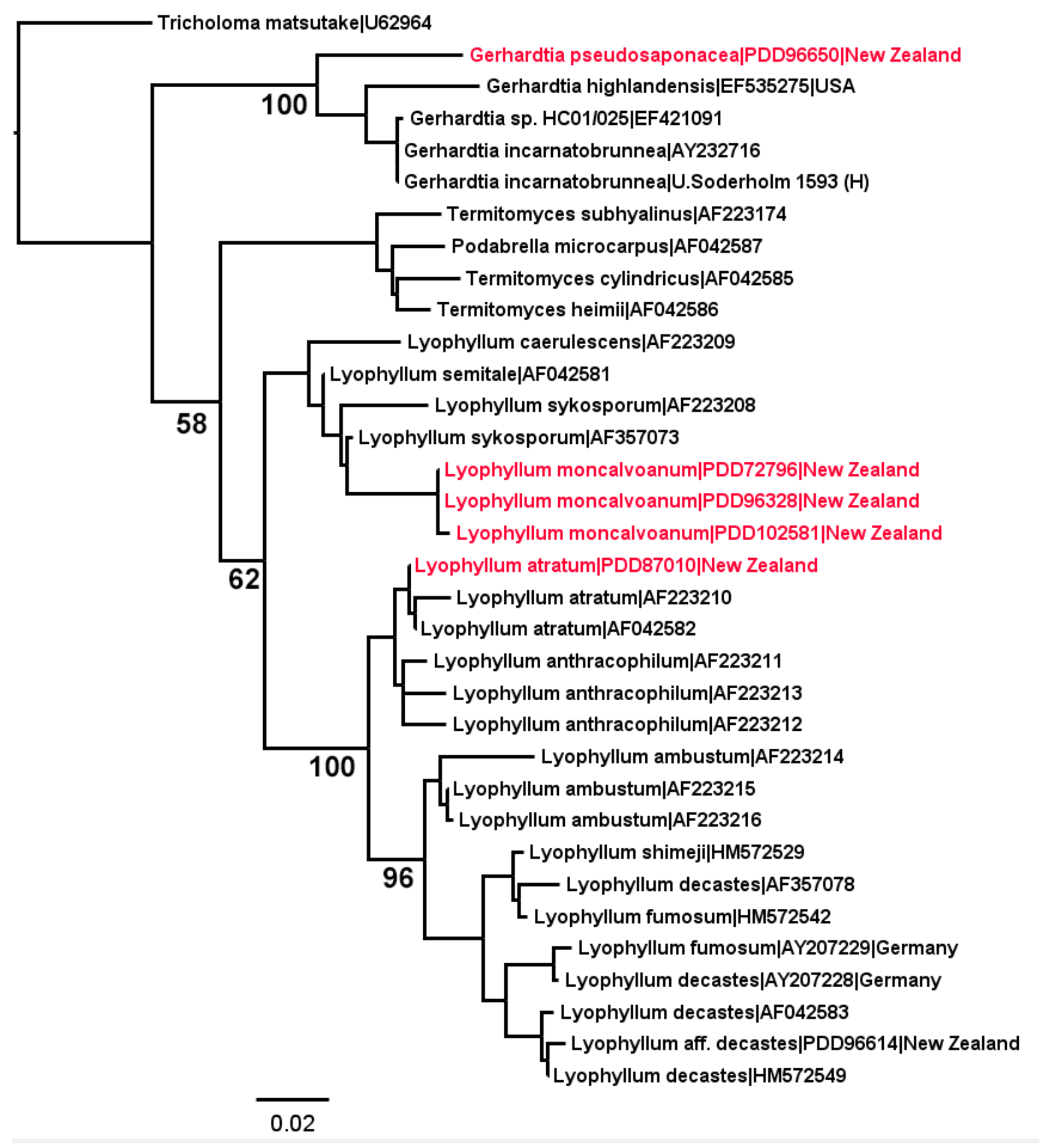

Fig. 6 - ML LSU phylogram of Gerhadtia pseudosaponacea, Lyophyllum moncalvoanum, Lyophyllum atratum and related sequences available in GenBank. The tree has been rooted with Tricholoma matsutake.

Hydnangium kanuka J.A. Cooper, sp. nov.

Fig. 7 IndexFungorum IF550157

Holotype - PDD 86860

Etymology - kānuka, from Māori for tea-tree, the recorded host tree for this ectomycorrhizal fungus.

Diagnosis - Hydnangium kanuka differs from the similar $H$. carneum in its association with the New Zealand tea-tree, Kunzea ericoides and Leptospermum scoparium.

Macromorphology - basidiomata subglobose with basal depression, 5 - $20 \mathrm{~mm}$ diameter, with a hyphal basal attachment binding soil. Gleba of irregular marbled locules appearing white and pink (8A2).Without columella but with small basal area becoming sterile. Peridium smooth, elastic when fresh and able to be peeled, white discolouring pale pink to dark pinkish-red (8A2 $8 \mathrm{C} 4)$, drying pale brown. Smell and taste none. 


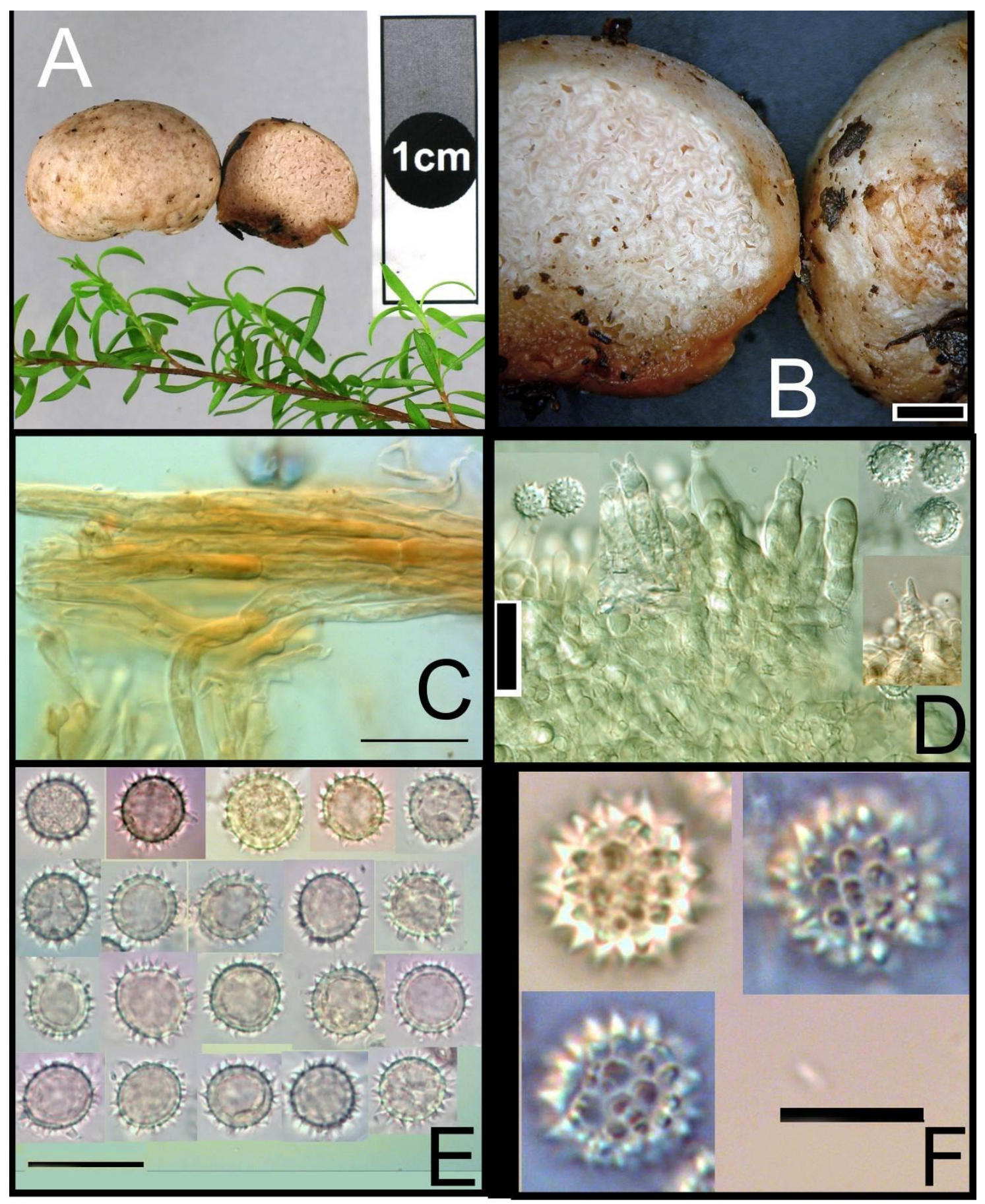

Fig. 7 - Hydnangium kanuka. A PDD 86860 Basidiomata. B gleba. C hyphae of peridium, in Melzer's reagent. D PDD 83715 basidia. E PDD 86860 spores. F spore spines, DIC illumination.

Micromorphology - peridium to $180 \mu \mathrm{m}$ thick, a parallel cutis of clamped hyphae, to $8 \mu \mathrm{m}$ diameter, without sphaerocysts, partially gelatinised in patches. Tramal plates to $150 \mu \mathrm{m}$ thick, gelatinised. Basidia 2-spored to $30 \times 6 \mu \mathrm{m}$, with sterigma to $6 \mu \mathrm{m}$. Spores hyaline, spiny, subglobose $11.8 \pm 0.9 \times 11.0 \pm 1.0 \mu \mathrm{m}, \mathrm{Q}=1.1 \pm 0.1$. Hilar appendage $1.3 \times 2.4 \mu \mathrm{m}$ truncate. Spines conical, to $2 \mu \mathrm{m}$ high and $1.5 \mu \mathrm{m}$ diameter at base.

Habitat - in soil associated with Kunzea ericoides and Leptospermum scoparium.

Known distribution and conservation status - endemic in New Zealand. Present in North Island and South Island.

Material examined - New Zealand, Mid Canterbury, Akaroa, Hinewai Reserve, in soil under Kunzea ericoides, 14th Feb 2004, J.A. Cooper, JAC8810 (PDD 79880). New Zealand, Mid Canterbury, Port Hills, Kennedys Bush Reserve, in soil under Kunzea ericoides, 23rd Jul, 2005, 


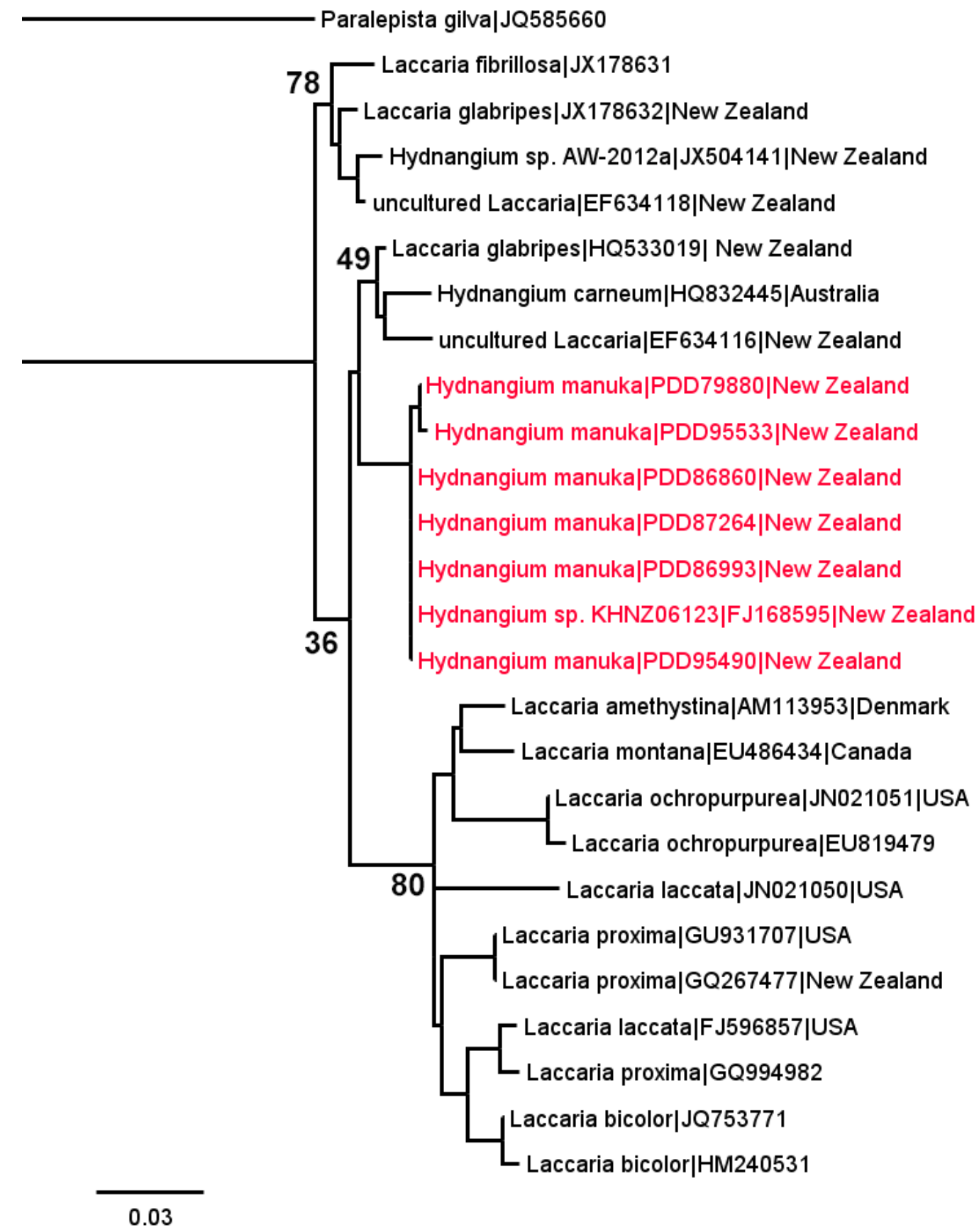

Fig. 8 - ML ITS phylogram of Hydnangium kanuka and selected sequences from GenBank. The tree has been rooted with Paralepista gilva.

J.A. Cooper, JAC9587 (PDD 83715). New Zealand, Mid Canterbury, Akaroa, Hinewai Reserve, in soil under Kunzea ericoides, 6th Jan 2006, J.A. Cooper, JAC9749 (PDD 86860 Holotype). New Zealand, Mid Canterbury, Kaituna Valley, in soil under Kunzea ericoides, 1st Apr 2006, J.A. Cooper, JAC9884 (PDD 9884). New Zealand, Mid Canterbury, Port Hills, Omahu Bush, in soil under Kunzea ericoides, $1^{\text {st }}$ Jan 2007, J.A. Cooper, JAC10174 (PDD 87264). New Zealand, Mid Canterbury, Port Hills, Kennedys Bush Reserve, in soil under Kunzea ericoides, 23th May, 2009, J.A. Cooper, JAC11039 (PDD 11039). New Zealand, Wellington, Rimutaka Forest Park, Cross Creek, in soil under Kunzea ericoides, 15th May 2009, J.A. Cooper, JAC11082 (PDD 95533). New Zealand, Mid Canterbury, Akaroa, Settler's Hill, in soil under Kunzea ericoides, 4th Aug 2012, J.A. Cooper, JAC12551 (PDD 96676). New Zealand, North Canterbury, Gore Bay, in soil under Leptospermum scoparium, $18^{\text {th }}$ May 2000, R.E. Beever, REB 1957 (PDD71779). 
GenBank - KJ461892 (PDD 79880. ITS), KJ461893 (PDD 86860. ITS), KJ461894 (PDD 86993. ITS), KJ461897 (PDD 87264. ITS), KJ461900 (PDD 95490. ITS), KJ461901 (PDD 95533. ITS),

Notes - on the basis of morphology alone it would appear difficult to separate $H$. kanuka from $H$. carneum which is ectomycorrhizal with Eucalyptus species. Sequence data (Fig. 8) supports the recognition of $H$. kanuka as a distinct taxon and it may be recognised by its host association. These data suggest New Zealand collections in PDD named H. carneum and Hydnangium sp. collected under Kunzea ericoides may be this species, although sequence data also suggest there is at least one further undescribed species (JX504141) which may show morphological separation. Further work is also required to determine the status of other similarly named collections associated with Leptospermum scoparium with introduced Eucalyptus and Pinus species, and the records of an association of Hydnangium with Nothofagus described by Chu-Chou and Grace (1983).

The semi-hypogeous truffle genus Hydnangium and the epigeous mushroom genus Laccaria are known to be con-generic within the Hydnangiaceae, and Hydnangium is the oldest available name. Conservation of the name Laccaria over Hydnangium is required in order to maintain stability.

Lyophyllum moncalvoanum J.A. Cooper \& P. Leonard, sp. nov.

Fig. 9 IndexFungorum IF550158

Holotype - PDD 96328

Etymology - Honouring Jean-Marc Moncalvo, a pioneer in the application of molecular techniques to our understanding of the phylogeny of Lyophyllum and the agaricoid fungi in general.

Diagnosis - ITS data indicate L. moncalvoanum is related to the clearly bruising species in section Lyophyllum where it is macroscopically similar to L. semitale but it differs in possessing globose spores and an insignificant bruising reaction.

Macromorphology - pileus $30-800 \mathrm{~mm}$ in diameter. Pileus shape applanate to centrally depressed. Pileus colour olivaceous black $(4 \mathrm{~F} 2-25 \mathrm{~F} 2)$ becoming drab, hygrophanous and with a greasy texture. Lamellae attachment adnate. Lamellae colour drab to olivaceous-buff. Lamellulae present in a series of three. Stipe cylindrical slightly enlarged towards base, $6-12 \times 50-90 \mathrm{~mm}$. Stipe colour clay buff to olivaceous buff, darkening towards base. Stipe flesh drab to olivaceous in colour; centrally hollow, tough in texture. Smell and taste not noted. Flesh bruising slowly darker with time but reaction not distinct. Basidiomata drying entirely black.

Micromorphology: spore print white. Spores hyaline, globose $5.0 \pm 0.5 \mu \mathrm{m}, \mathrm{n}=20$. Basidia 4-spored, basidia $30-40 \times 6-8 \mu \mathrm{m}$, clavate. Basidia with indistinct siderophilous granules. Pileipellis gelatinised, irregular, with brown intra-cellular pigment. Clamps not observed in any tissue. Lamellae without cheilocystidia or pleurocystidia.

Habitat - Solitary to fasciculate in soil, saprophytic, under Nothofagus and Kunzea.

Known distribution and conservation status - seemingly widespread in beech and beech/teatree forests in North and South Islands.

Material examined - New Zealand, Taupo, Clements Mill Road, Cascades Track, in soil with Nothofagus, 16th May 2011, P.K. Buchanan, JAC12088 (PDD 96328 Holotype). New Zealand, Taupo, Waikiri Scenic Reserve, in soil with Kunzea ericoides, 16th May 2011, T. Garland, JAC12092 (PDD 96332). New Zealand, Nelson Lakes, Lake Rotoiti, in soil with Nothofagus menziesii, 21st Mar 2004, P. Leonard, PL158404 (PDD102581). New Zealand, Taupo, Mt Tongariro, 16th May 2005, E. \& A. Horak, ZT9697 (PDD 72796).

GenBank - KJ461890 (PDD 72796. ITS), KJ461891 (PDD 72796. LSU), KJ461904 (PDD 96328. ITS), KJ461905 (PDD 96328. LSU), KJ461906 (PDD 96332. ITS), KJ461912 (PDD 102581. LSU).

Notes - Hofstetter et al 2002 have carried out the most extensive recent analysis of Lyophylleae and demonstrated Lyophyllum species fall into three separate groups. The type species of the genus, Lyophyllum leucophaeatum, appears in a clade containing Calocybe. In order to 
maintain the generic name for many commonly encountered drab coloured species of Lyophyllum it was proposed for conservation with the new type L. semitale (Redhead et al. 2006).

The sequence data confirm Lyophyllum moncalvoanum is a member of the subgenus Lyophyllum, (Fig. 6) characterised by basidiomata bruising grey or blue and becoming black. In $L$. moncalvoanum the reaction is less pronounced but the basidiomata dry entirely black. This and the introduced L. atratum are the only reported species of Lyophyllum from New Zealand but existing collections in the PDD fungarium indicate additional species remain to be discovered and named.

Some members of the Lyophyllaceae have been reported to be ectomycorrhizal. Recent isotopic analysis (Hou et al 2012) suggests members of the Lyophyllaceae clade are not ectomycorrhizal.

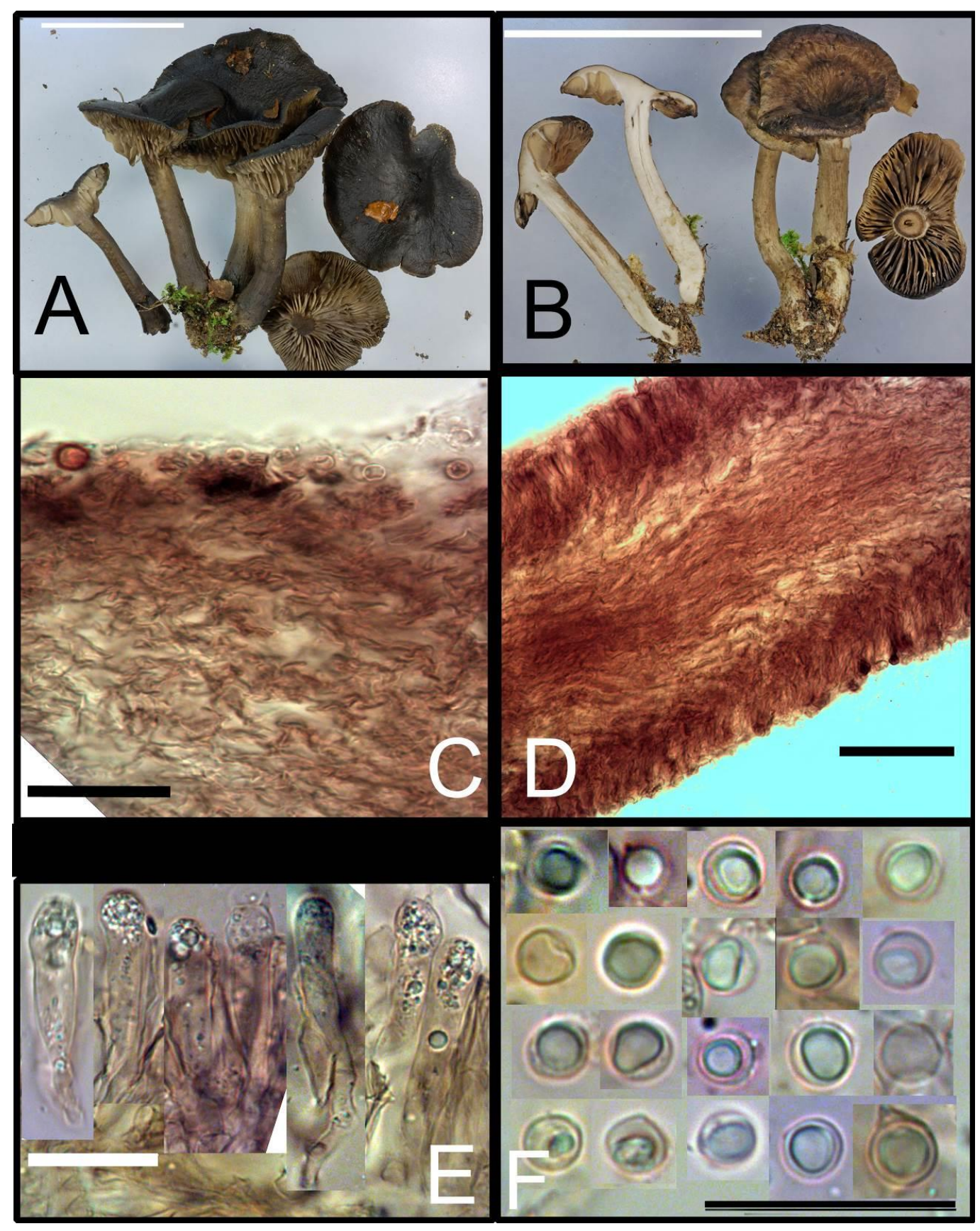

Fig. 9 - Lyophyllum moncalvoanum. A PDD 96328 basidiomata. B PDD 96332 basiomata. C PDD 96328 Pileus vertical section, in Melzer's reagent. D lamellar trama section, DIC illumination. E basidia, in $\mathrm{KOH}$. F spores, in $\mathrm{KOH}$. 
Mycena stevensoniae J.A. Cooper, nom. nov.

Fig. 10

IndexFungorum IF550159

Basionym - Crinipellis roseola G. Stev., Kew Bulletin 19(1): 42 (1964)

Non Mycena roseola (Murrill) Murrill, Mycologia 8(4): 221 (1916)

Macromorphology - Pileus 3-7mm diameter. Pileus shape convex, sometimes umbonate. Pileus texture radially translucent striate, minutely pruinose when dry. Pileus colour pale pink (11A2 - 11B3); colour intensified on drying and becoming orange tinted. Lamellae concolorous with cap or paler; edge concolorous. Lamellae attachment arcuate. Lamellulae present and short. Stipe equal $0.5-1 \times 10-30 \mathrm{~mm}$. Stipe concolorous with pileus, sometimes developing yellow tints towards base. Stipe texture slightly viscid when wet, pruinose at apex. Stipe flesh without latex. Stipe base insititious, sometimes with a few attachment fibres. No significant smell or taste.

Micromorphology - Pileipellis a thin gelatinised cutis with surface diverticulae to $7 \times 2 \mu \mathrm{m}$. Pileal subcutis of weakly dextrinoid, hymeniform cells to $20 \mu \mathrm{m}$ diam. Basidia cylindrical, to $20 \times$ $6 \mu \mathrm{m}$, sterigma to $7 \mu \mathrm{m}$ long. Basidioles similar to basidia. Lamellar trama weakly dextrinoid. Spores hyaline, amyloid, cylindrical, $6.2 \pm 0.6 \times 3.3 \pm 0.3 \mu \mathrm{m}, \mathrm{Q}=1.9 \pm 0.2, \mathrm{n}=25$ (measurements including apiculus). Pleurocystidia not observed. Cheilocystidia, when present, to $30 \times 4 \mu \mathrm{m}$, sparse and irregular towards apex. Stipitipellis of parallel, clamped, weakly dextrinoid hyphae, to 8 $\mu \mathrm{m}$ diameter. Surface hyphae partially gelatinised, with diverticulate hyphae to $20 \times 2 \mu \mathrm{m}$.

Habitat - This is a common tiny pink Mycena on beech (Nothofagus) leaves where it causes a bleaching of the leaf tissue.

Known distribution and conservation status - common in beech forest (Nothofagus fusca and $N$. solandri) in North Island and South Island.

Material examined - New Zealand, Wairarapa, Mt Holdsworth, Gentle Annie Track, on fallen leaves of Nothofagus fusca, 11th May 2007, J.A. Cooper, JAC10338 (PDD 87426). New Zealand, Taupo, Ohakune, Mountain Road, Blyth Track, on dead twigs and leaves of Nothofagus solandri, 21st Apr 2009, J.A. Cooper, JAC10988 (PDD 95443). New Zealand, mid Canterbury, Lyndon Saddle Track, on dead leaves of Nothofagus solandri, 3rd May 2010, J.A. Cooper, JAC11369 (PDD 95829). New Zealand, north Canterbury, Arthurs Pass, Bridal Veil Track, on dead leaves of Nothofagus solandri, 6th May, 2010, J.A. Cooper, JAC11436 (PDD 95847). New Zealand, Taupo, Kaimanawa Forest Park, Clements Mill Road, on dead leaves and twigs of Nothofagus fusca, 18th May, 2011, J.A. Cooper, JAC12019 (PDD 96008).

GenBank - JQ694102 (PDD 96008. ITS)

Notes - The species has been known by the author for a number of years but the connection with Stevenson's Crinipellis roseola was only recently made. The original placement of this species in Crinipellis by Stevenson was not justified by her description of the morphology. Horak 1971 examined the type but concluded the material was insufficiently preserved to make any conclusion on taxonomic placement. Kerekes and Desjardin 2009 examined the type and concluded the material represented a species of Mycena but refrained from making the transfer until more material was available for a better diagnosis.

To date there has been no detailed phylogenetic study of the genus Mycena but it is recognised the genus is polyphyletic. The analysis presented in Figure 11 includes a core group of Mycena with GenBank identifications of mainly European material belonging to sections Polyadelphia, Fragilipedes, Fuliginellae, Lactipedes, Supinae, Rubromarginatae, Luculentae, Filipedes, Mycena, Cinerellae, Intermediae (after Robbich 2003) and also includes Favolaschia, Dictypanus, Cruentomyces, Panellus and Resinomycena. There is an urgent need for a robust multilocus phylogenetic revision to clarify taxonomic boundaries for Mycena and related genera. Morphologically M. stevensoniae conforms to the current concept of Mycena which is where I have placed it at this stage. 


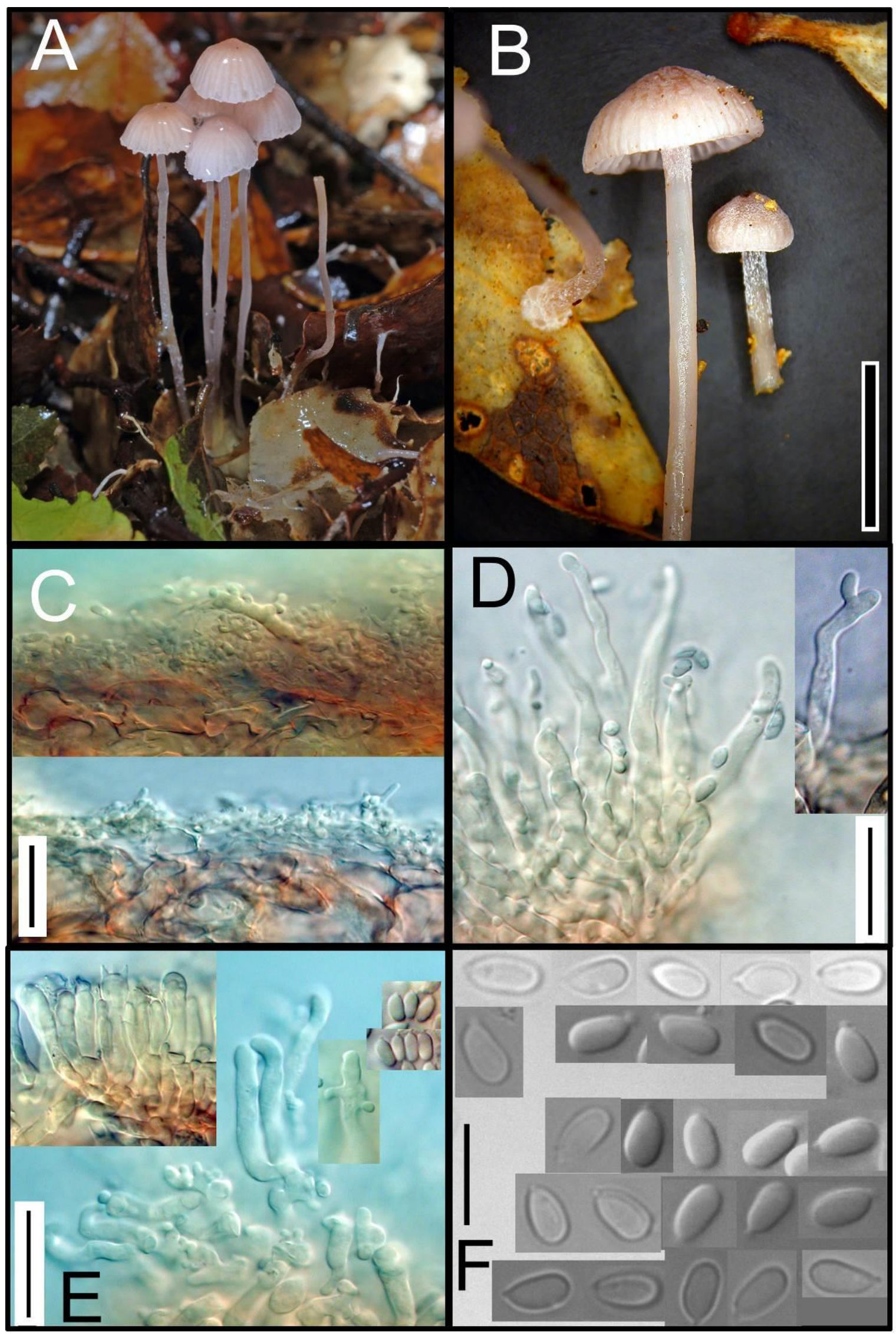

Fig. 10 - Mycena stevensoniae. A PDD 96008: in leaf litter of Nothofagus fusca. B PDD 87426 detail, and associated bleached leaf, scale $=5 \mathrm{~mm}$. C two vertical sections of pileipellis, in Melzer's reagent, scale $=20 \mu \mathrm{m}$. D caulocystidia, scale $=20 \mu \mathrm{m}$. E basidia (inset), spores (inset) and lamellar edge, in Melzer's reagent, scale $=20 \mu \mathrm{m}$. F spores, in $\mathrm{KOH}$, scale $=10 \mu \mathrm{m}$. 


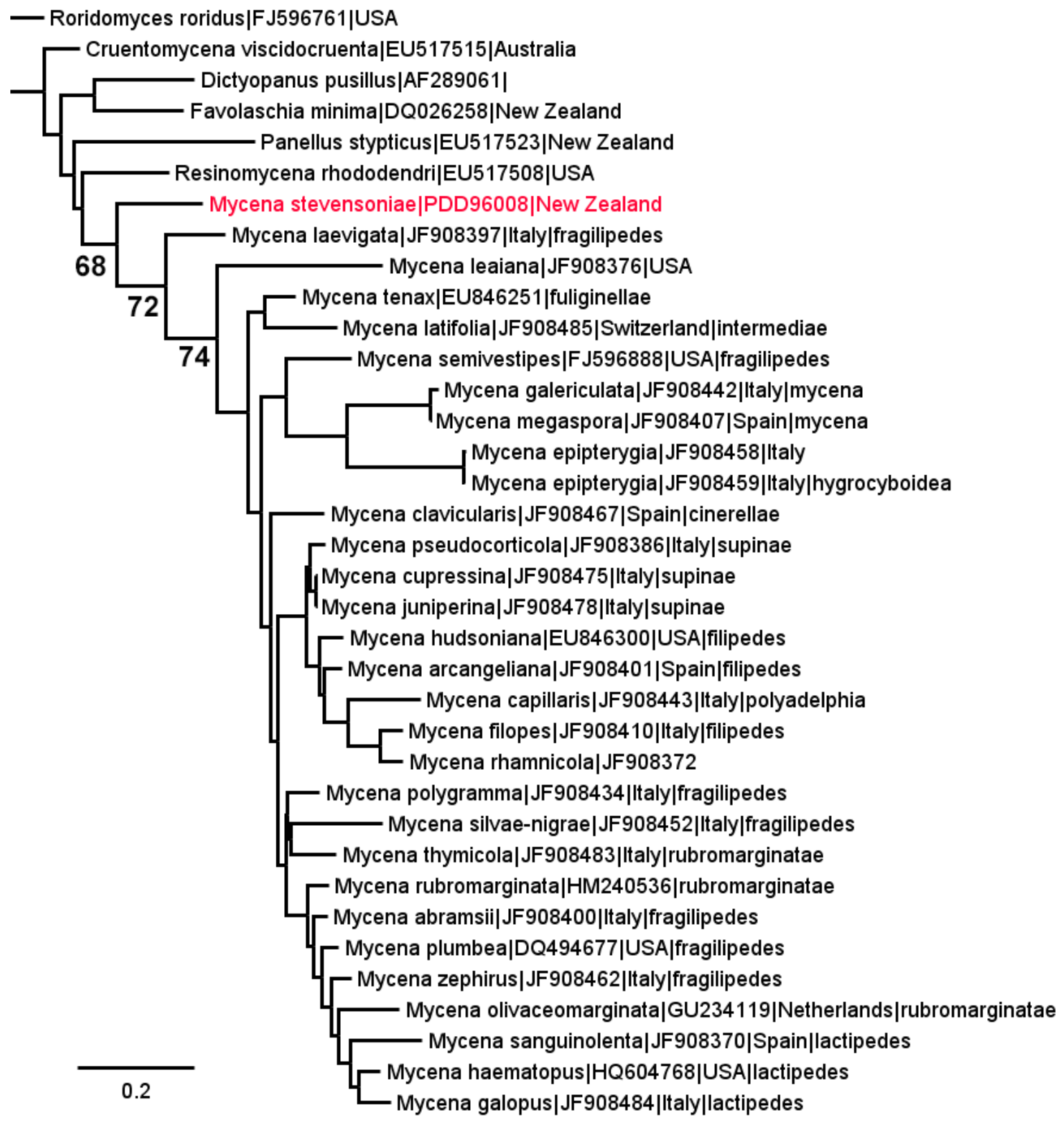

Fig. 11 - ML ITS phylogram of Mycena stevensoniae and related sequences from GenBank. The tree was rooted with Roridomyces roridus.

Rhodocollybia purpurata (G. Stev.) J.A. Cooper, comb. nov.

Figs $12-13$ IndexFungorum IF550160

Basionym - Pluteus purpuratus G. Stev., Kew Bull. 16(1): 73 (1962).

$\equiv$ Lepiotula purpurata (G. Stev.) E. Horak, New Zealand Journal of Botany 9: 448 (1971)

$\equiv$ Lepiota purpurata (G. Stev.) E. Horak, Sydowia 33: 129 (1980).

Macromorphology - Pileus $25-65 \mathrm{~mm}$ diameter, surface innately fibrillose and rugulose, initially hemispherical, flattening or slightly upturned, with indistinct umbo. Colour when dry greyish magenta (13E3), with cream to pale pink areas of fine fibrils; when fresh nearly black to dark violet (17F8). Context of pileus cream. Lamellae crowded, edges uneven, sometimes mottled. Lamellae attachment adnexed to subfree. Lamellae colour orange grey, reddish grey, to brownish grey $(8 \mathrm{~B} 2-6 \mathrm{~B} 2-6 \mathrm{C} 2)$. Lamellulae present in a single series of irregular length. Stipe $30-70 \times 4$ $-8 \mathrm{~mm}$ at apex, with basal bulb $8-24 \mathrm{~mm}$ diameter. Colour similar hues to cap but paler, surface texture longitudinally fibrillose. Context of stipe white, fibrous, tough, hollow. Basal bulb with white hyphae binding litter. Spore print cream. No significant smell or taste. 


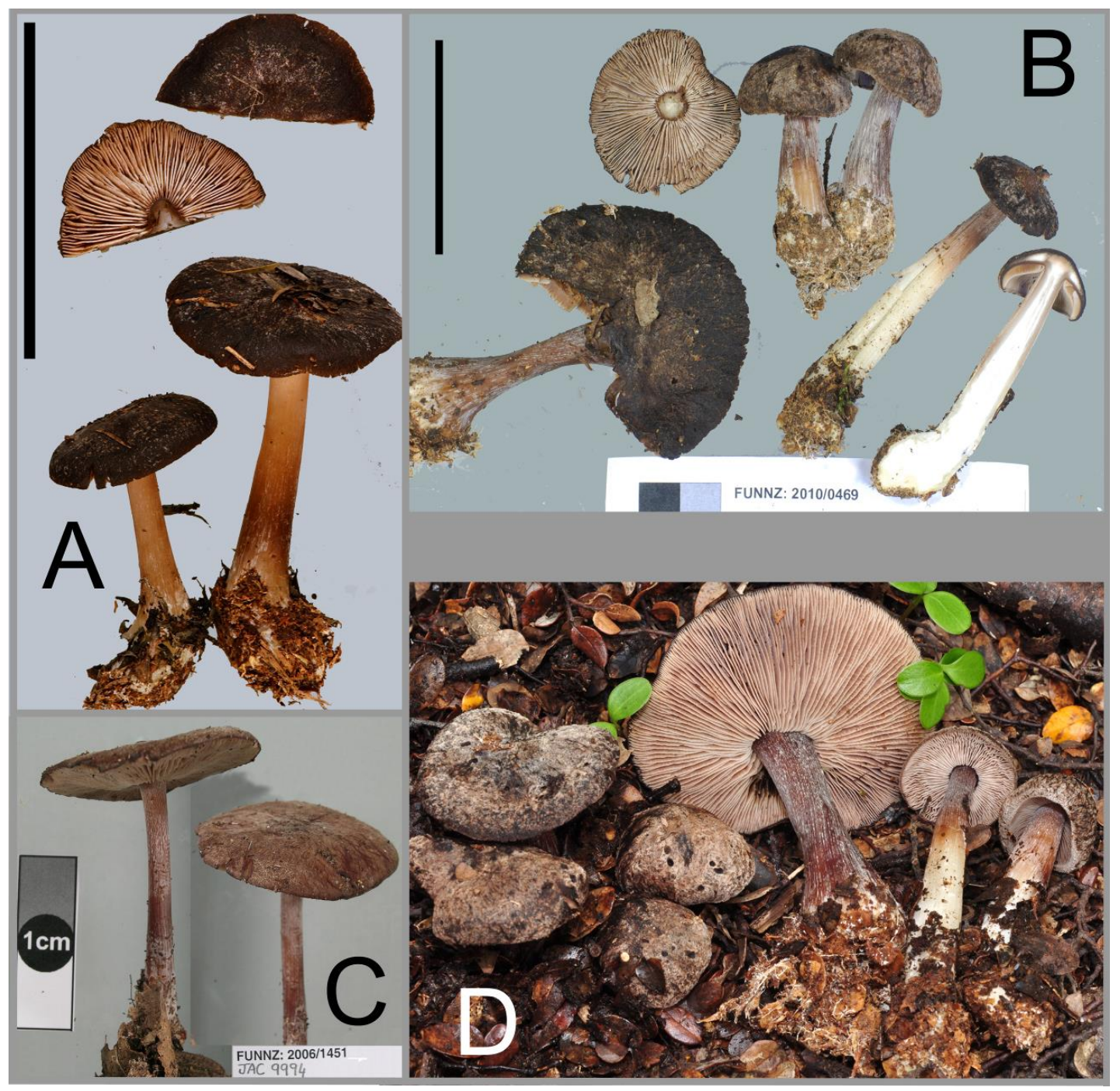

Fig. 12 - Rhodocollybia purpurata basiomata appearance. A PDD 87645. B PDD 95837. C PDD 87094. D PDD 95837.

Micromorphology - Collapsed basidiospores truncate dextrinoid basidiospores $7.7 \pm 0.8 \times$ $3.7 \pm 0.4 \mu \mathrm{m}, \mathrm{Q}=2 \pm 0.3, \mathrm{n}=20$ (including apiculus). Uncollapsed basidiospores lacrymoid hyaline, from spore print $8.2 \pm 0.5 \times 3.6 \pm 0.4 \mu \mathrm{m}, \mathrm{Q}=2.3 \pm 0.3, \mathrm{n}=10$. Basidia clavate 4sterigmate, hyaline, $25-30 \times 6-8 \mu \mathrm{m}$. Sterigma to $5 \mu \mathrm{m}$. Pleurocystidia absent. Cheilocystidia abundant, clavate to cylindrical, flexuose, to $30 \times 6 \mu \mathrm{m}$. Pileipellis a clamped radial cutis. Surface fibrils of hyaline repent hyphae $6-11 \mu \mathrm{m}$ diameter. Cutis hyphae weakly dextrinoid, with brown zebroid encrusted pigment. Lamellar trama weakly dextrinoid, parallel. Stipitipellis a longitudinal cutis of pale brown, weakly dextrinoid hyphae $3-4 \mu \mathrm{m}$ diam. Stipitipellis with surface diverticulae, to $60 \times 3-6 \mu \mathrm{m}$.

Habitat - gregarious amongst litter in beech forest and tea-tree scrub.

Known distribution and conservation status - widely distributed in in North Island and South Island.

Material examined - New Zealand, Nelson. Karamea, Oparara Arches, on mossy bole of Nothofagus menziesii, 11th May 2006, J.A. Cooper, JAC 9994 (PDD 87094). New Zealand, Taupo, Whakapapa, Whakapanui Walk, on soil under Nothofagus solandri 21st Apr 2009, J.A. Cooper, JAC10992 (PDD 95447). New Zealand, Dunedin, Waiora Scout Camp, on soil under Kunzea ericoides, 12th May 2008, G. Gates \& D. Ratkowsky, JAC10654 (PDD 87541). New Zealand, Dunedin, Swampy Spur, Steve Amie's Track in litter under Leptospermum scoparium, 13th May 2008, T. Garland, JAC10800 (PDD 87645). New Zealand, Mid-Canterbury. Waimakariri River 


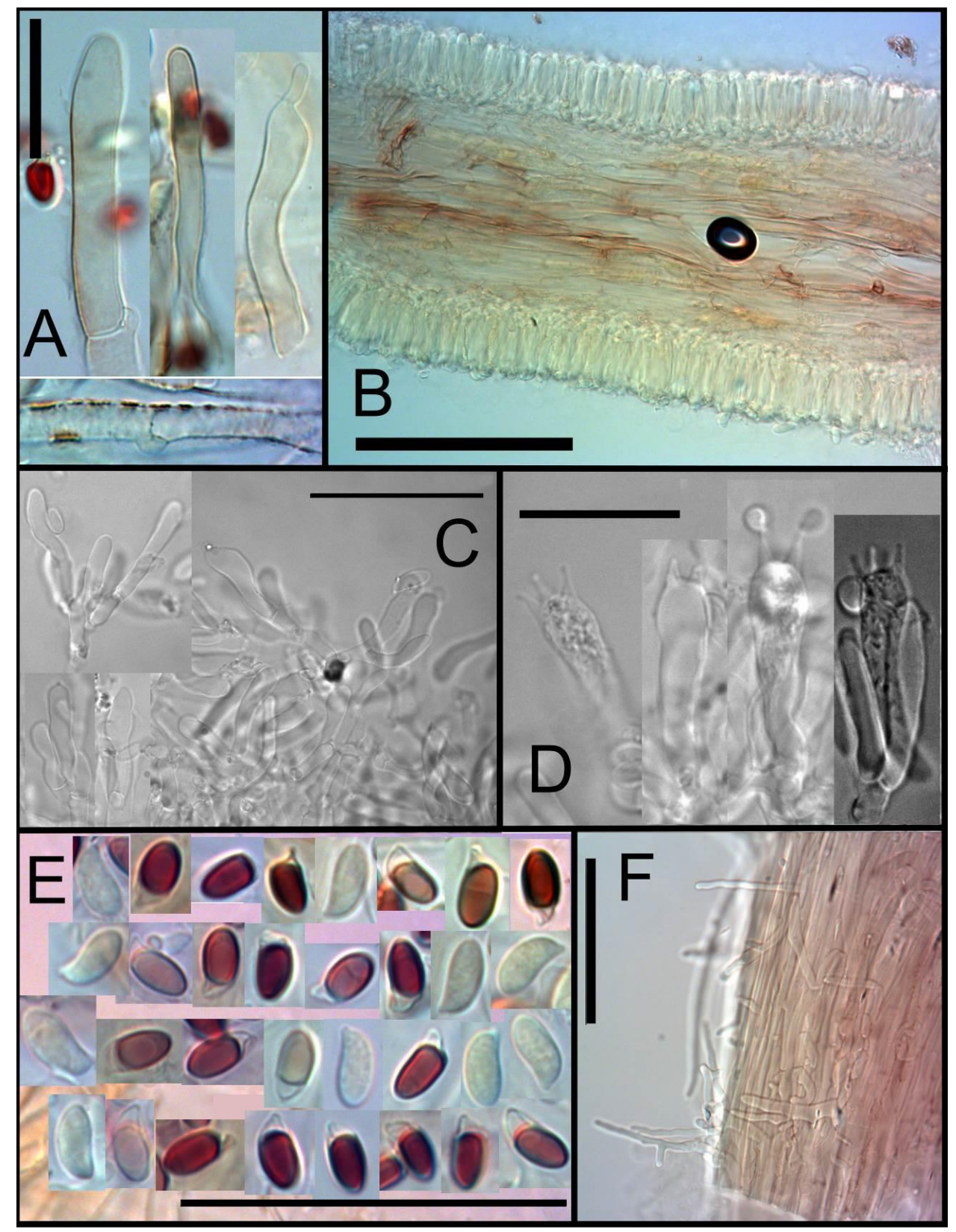

Fig. 13 - Rhodocollybia purpurata micromorphology. A PDD 95837 upper: pileipellis terminal hyphae, lower: cuticular hyphae with clamp and zebroid brown encrusted pigment. B lamellar trama, in Melzer's reagent. C cheilocystidia. D basidia. E basidiospores from deposit on pileus, in Melzers' showing dextrinoid endospore. F stipitipellis with diverticulate surface hyphae.

Track, in litter of Nothofagus solandri, 3rd May 2010, N. Siegel, JAC11373 (PDD 95837). New Zealand, Mid-Canterbury, Bankside Scientific Reserve, in litter under Kunzea ericoides, 22nd April 2010, J.A. Cooper, JAC11799 (PDD 96196).

GenBank - HQ533009 (PDD 96837. ITS).

Notes - Rhodocollybia purpurata can be variable in appearance, with stipes from a robust to slender appearance, and the entire fresh basidiomata dark and weakly translucent in moist conditions to paler, opaque and frosted in drier conditions. In dried material of $R$. purpurata the adnate lamellae pull away from the stipe and so appear to be free. Horak 1980 indicated the 'free gills', combined with the pinkish grey colour of the mature lamellae, are probably what led Stevenson to make the original combination in Pluteus. Horak examined the holotype and indicated it was in poor condition. He observed truncate dextrinoid basidiospores, which combined with the 
presence of 'free gills' led him to place the fungus in Lepiotula, now considered to be the group of spur-spored or truncate-spored Lepiota species. Examination of recently collected material, together with a re-examination of the holotype (Johnston 2010) indicate that only a proportion of the spores are dextrinoid, often those deposited on the pileus, and not those in a basidiospore print. In addition, and crucially, only the endospore is dextrinoid and it often retracts from the apicular region of the spore. Sometimes the hyaline outer wall remains observable but in dried material it too collapses. Thus the dextrinoid, collapsed basidiospores may often appear to be truncate, like Lepiotula. The reaction is characteristic of Rhodocollybia species (Lennox 1979). Rhodocollybia purpurata is typical of the genus except for the spore print being cream rather than pink, even though the mature lamellae have a pale grey/orange/pink appearance. Basic phylogenetic analysis of the ITS region (Figure 14) places it with the Rhodocollybia butyracea group (Hughes et al 2010), with Rhodocollybia currently classified in the Omphalotaceae. It is closely related to $R$. pandipes described from Costa Rica. $R$. purpurata differs from both $R$. butyracea and $R$. pandipes in the dark greyish purple colouration of the cap. The genus currently contains 29 assigned species (Species Fungorum 2013) of which only R. sleumeri (Singer) Halling is also described from nonequatorial southern hemisphere (Argentina).

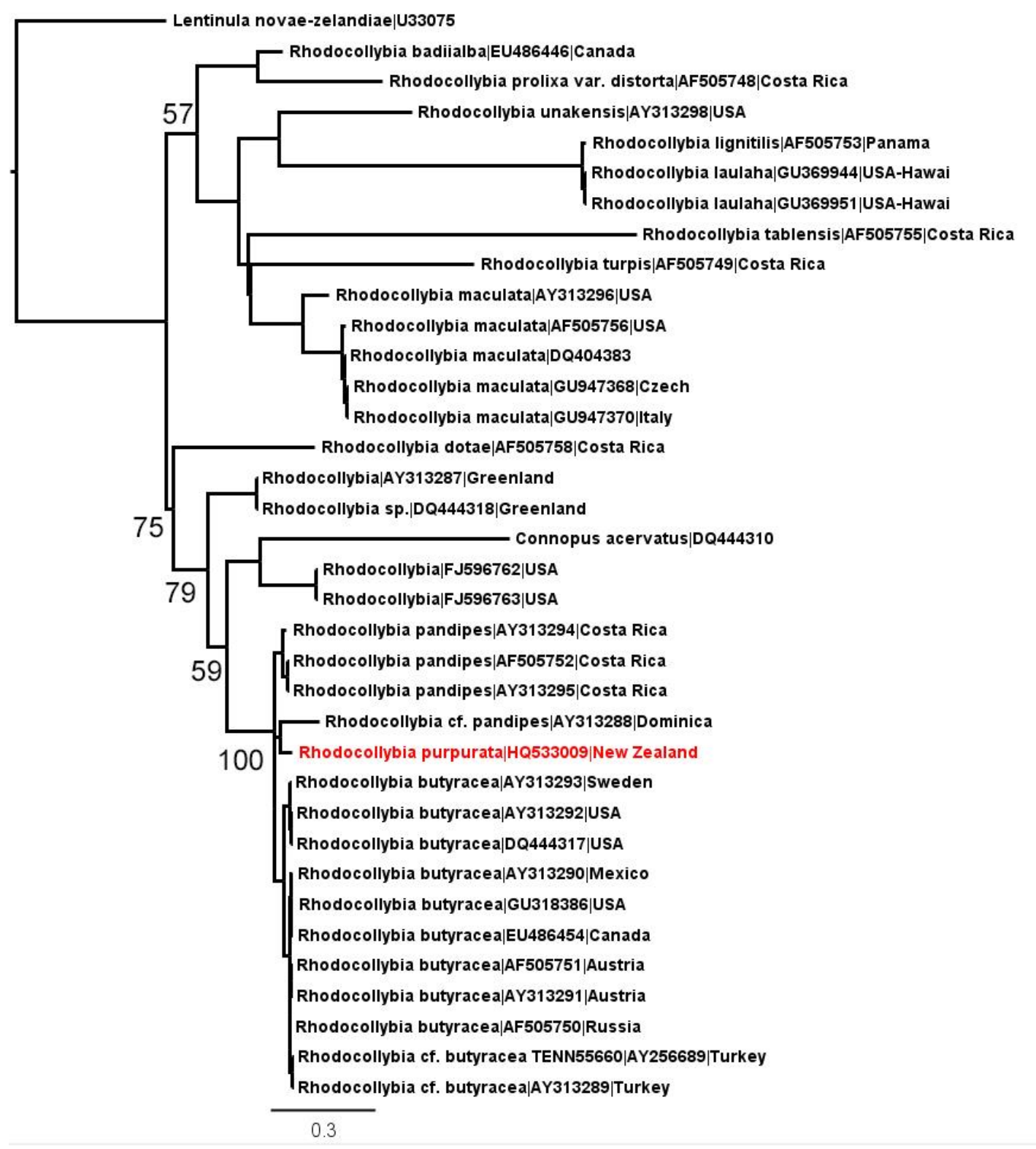

Fig. 14 - ML ITS phylogram of Rhodocollybia purpurata and selected related sequences from GenBank. The tree was rooted with Lentinula novae-zelandiae. 
IndexFungorum IF550161

Basionym - Hygrophorus waikanaensis G. Stev., Kew Bulletin 16(3): 375 (1963)

? $\equiv$ Trogia odorata Corner, Gdns' Bull., Singapore. Supplement 2: 60 (1991)

Macromorphology - Pileus 10 - 30mm diameter, hemispherical, becoming depressed towards centre, edge inrolled. Colour dark leaden grey (19E4), with sparse adpressed greyish magenta fibrils (13E4). Context of pileus white becoming blue towards stem attachment. Lamellae decurrent, moderately thick, violet white (18A2), occasionally forked. Lamellulae few, irregular. Stipe $8-35 \times 3-7 \mathrm{~mm}$. Stipe central, surface minutely fibrillose, concolorous with pileus. Context of stipe violet white to darker, hollow. Texture rubbery. Smell and taste strongly of aniseed.

Micromorphology - Basidiospores inamyloid, cyanophilous, with prominent apiculus, subglobose, $4.9 \pm 0.3 \times 3.4 \pm 0.3 \mu \mathrm{m}, \mathrm{n}=10$ (including apiculus). Basidia to $60 \mu \mathrm{m} \times 6 \mu \mathrm{m}, 4$ spored, without siderophilous granules, without basal clamp, sterigma to $3 \mu \mathrm{m}$. Lamellar trama intermixed. Pleurocystidia and cheilocystidia absent. Pileipellis an unclamped, ungelatinised, dense hyaline cutis with hyphae $3 \mu \mathrm{m}$ in diameter, often glassy walled. Surface hyphae with brown plasmatic and zebroid encrusted pigment, faintly amyloid, with some erect terminal elements. Terminal elements cylindrical or occasionally present as swollen vesicles. Sub-cutis with gloeoplerous hyphae. Stipitipellis of glassy-walled parallel, unbranched, unclamped hyphae, to 3 $\mu \mathrm{m}$ in diameter, accompanied by long gloeoplerous hyphae, to $8 \mu \mathrm{m}$ diameter. Caulocystidia present along entire stipe, cylindrical or swollen and irregular, with brown plasmatic content. Sarcodimitic construction (Redhead, 1987) observed in the hymenophoral trama and stipitipellis. Here I am using the term sarcodimitic in a broad sense to indicate the presence of broad, long (but not necessarily fusiform), noticeably gloeoplerous hyphae, together with thinner, non-gloeoplerous (and not necessarily branching) 'generative' hyphae.

Habitat - basidiomata clustered and strongly fasciculate on well-rotted wood (white rot).

Known distribution and conservation status - known from only a few localities in North Island and South Island. The readily recognisable appearance of fresh material suggests the species is genuinely scarce. A number of recent collections are from modified habitats and it is possible the fungus has been introduced to New Zealand.

Material examined - New Zealand, Mid-Canterbury, Port Hills, Kennedy's Bush, on dead log, 6th Feb 2005, J.A. Cooper, JAC9233 (PDD 80685). New Zealand, Taupo, Ohakune, Marshall's Rd., on dead wood, 4th April 2005, C. Shirley (PDD 80757). New Zealand, Mid-Canterbury, Port Hills, Kennedy's Bush, on dead wood of Plagianthus regius, 30th Jan 2006, J.A. Cooper, JAC9787 (PDD 86898, culture ICMP16487). New Zealand, Mid-Canterbury, Christchurch, Travis Wetland Park, on dead stump of Salix fragilis, 16th Mar 2008, C. Meurk, JAC10412 (PDD 87665). New Zealand, Mid-Canterbury, Christchurch,Travis Wetland Park, on dead branch of Salix fragilis, 23rd Mar 2008, J.A. Cooper, JAC10426 (PDD 87667). New Zealand, Hawke's Bay, Tutira, on dead Kunzea ericoides wood, M. Wassilieff (PDD 90281). New Zealand, Wellington, Butterfly [Creek], on dead rotten log of Nothofagus truncate, 22nd Mar 1980, G. Stevenson, GS 80/68 (PDD 90282). New Zealand, B.P. Segedin (as Hygrotrama sp.), BPS 2591 (PDD 91863)

GenBank - JQ694117 (PDD 87667. ITS)

Notes - This striking fungus was collected a number of times before the connection with Stevenson's name was made. Existing herbarium collections, including the type, appear to be dominated by immature basidia, without sterigmata and with few free basidiospores. The material suggests the basidia also mature rapidly and then collapse, thus making their observation difficult. Stevenson's original placement of it in Hygrophorus is understandable because of thick, decurrent lamellae and the long basidia. However, it also has anomalous features such as growth on wood and a firm rubbery context. Horak 1971 examined the type and indicated placement near Hydropus or Gerronema on the basis of cuticle and cystidial structures. This assertion is confirmed by sequence analysis of recent material (Figure 17) which places the fungus in the /hydropoid clade (Moncalvo et al. 2002), currently recognised as the Porotheliaceae. The clade contains sequences labelled Clitocybula (Type C. lacerata (Scop.) Métrod 1952), Hydropus (Type H. fuliginarius (Batsch) 


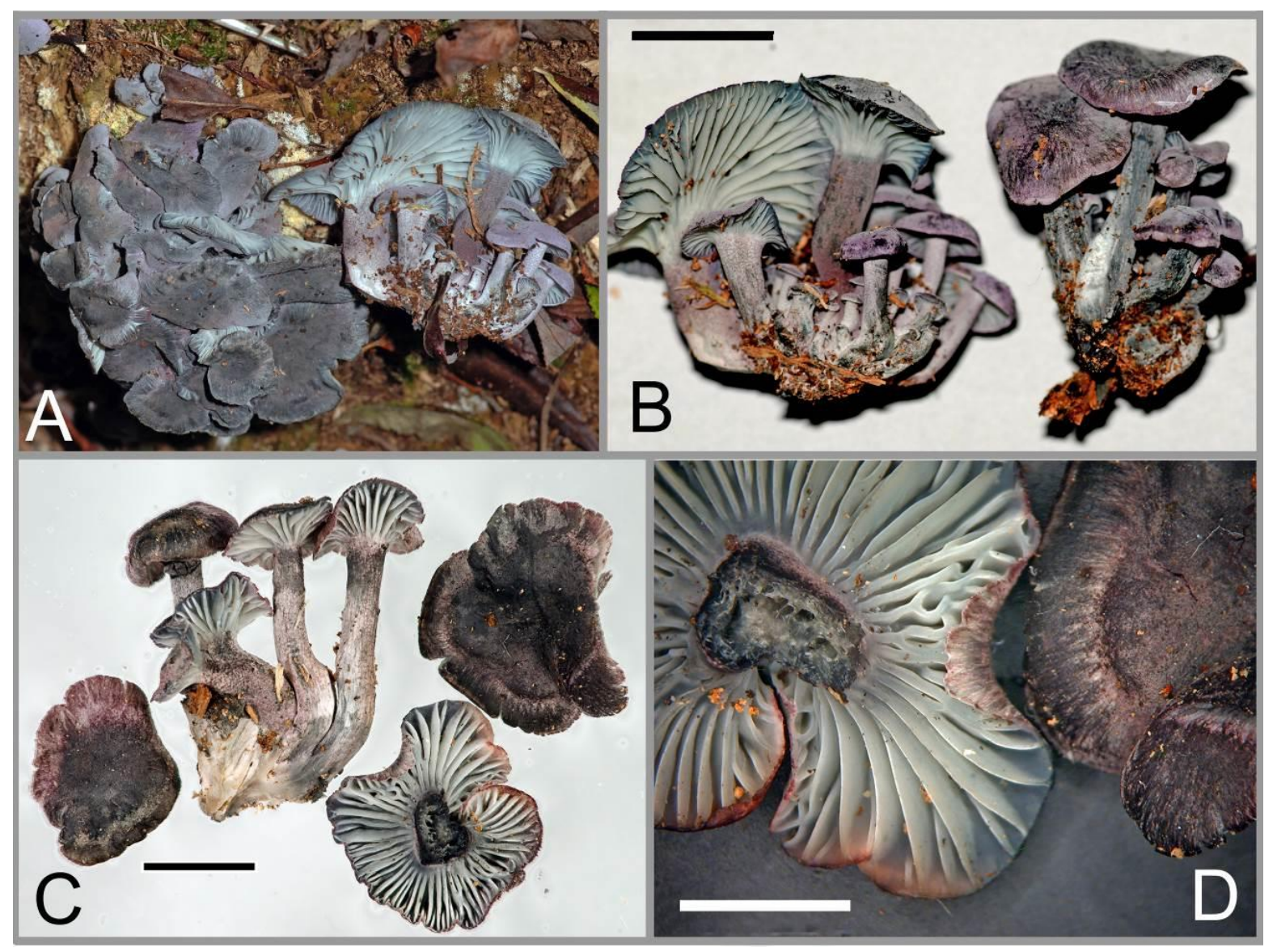

Fig. 15 - Basidiomata of Gerronema waikanaensis . A-B PDD 87667, bar $=20 \mathrm{~mm}$. C PDD 87665 , bar $=10 \mathrm{~mm}$. D PDD 87665, bar $=5 \mathrm{~mm}$.

Singer 1943), Gerronema (Type G. melanomphax Singer 1951), Trogia (Type T. montagnei Fr. 1836), Delicatula (Type D. integrella (Pers.) Fayod 1889), Porotheleum (Type P. fimbriatum (Pers.) Fr. 1818), Mycopan (Type M. scabripes (Murrill) Redhead, Moncalvo \& Vilgalys $2013 \equiv$ Hydropus scabripes) and Megacollybia (Type M. platyphylla (Pers.) Kotl. \& Pouzar 1972). Singer 1986 placed Hydropus, Clitocybula and Gerronema in different tribes whilst explicitly noting the close relationship between them. Following Moncalvo et al. 2002 the relationship was examined using molecular data by a number of authors (e.g. Redhead 2002). Antonin et al 2008 suggested the generic name Clitocybula should be applied to many taxa in the /hydropoid clade, excluding some basal taxa, including the well-known Megacollybia platyphylla, a position which appears inappropriate as a consequence of subsequent sampling. Recently described species, together with supporting molecular data, have been assigned to some of these genera, for example Clitocybula (Maysheva et al. 2010, Antonin et al. 2011), Trogia (Yang et al. 2012), Gerronema (Antonin et al. 2008), Megacollybia (Hughes et al. 2007). In the absence of more definitive generic delineation Hygrophorus waikanaensis has been assigned to Gerronema. Increased molecular sampling, especially of the common tropical and southern hemisphere species in Trogia, Gerronema, Delicatula and the related reduced forms is necessary to increase our knowledge and circumscription of robust generic boundaries within the Porotheliaceae.

From the published description (Corner 1991) it is likely that Trogia odorata Corner, described from very rotten wood in the Solomon Islands, is a later synonym, or at least closely related. It should be noted that a member of the same group, Trogia venenata, is suspected of containing a lethal toxin responsible for hundreds of deaths in China (Yang et al 2012) and caution is necessary when considering the edibility G. waikanaensis. 


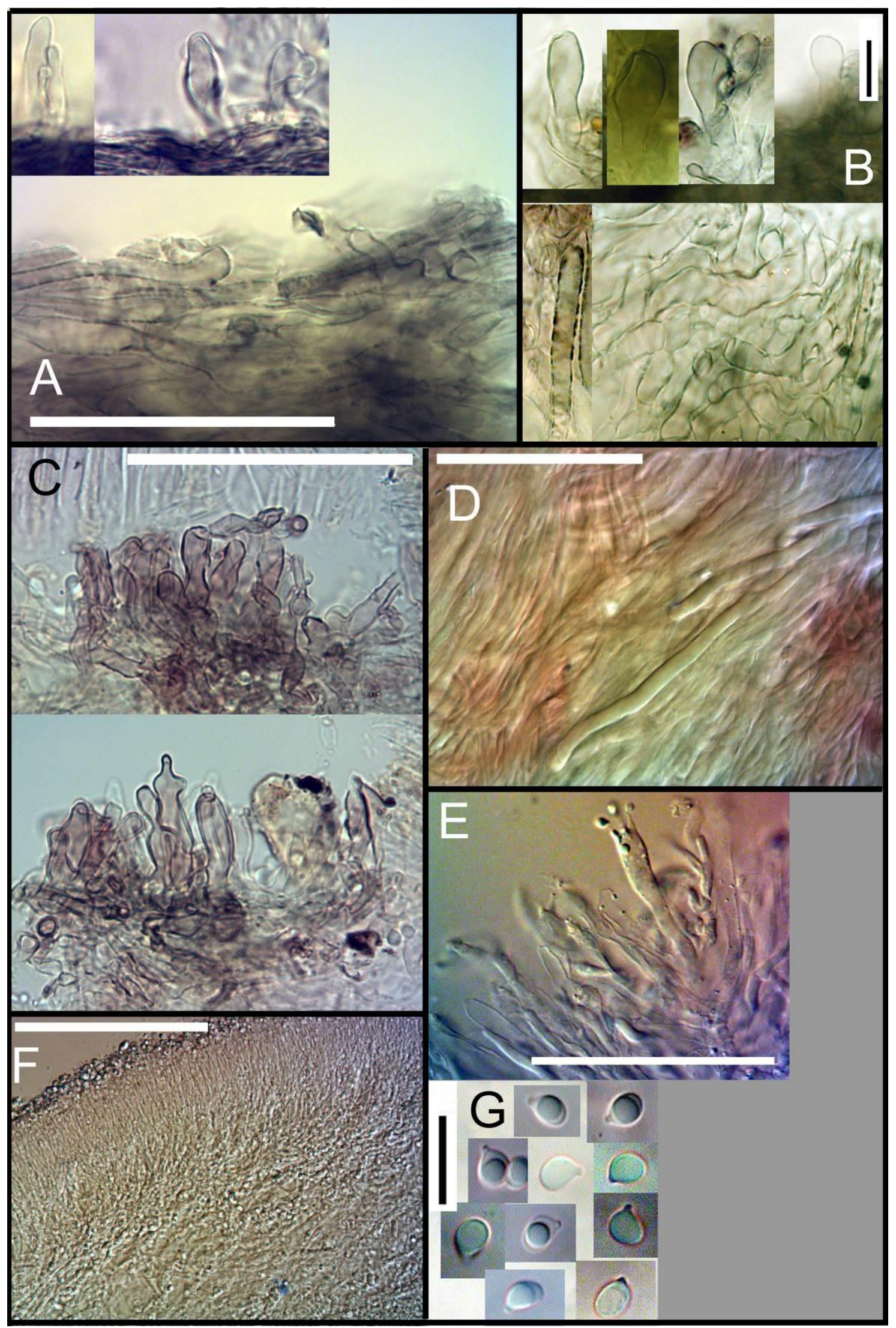

Fig. 16 - Micromorphology of Gerronema waikanaiensis. A PDD 80685 upper: pilocystidia, lower: verticle section through pileipellis, bar $=50 \mu \mathrm{m}$. B PDD 87665 upper: pilocystidia, lower: squash of pileipellis, bar $=10 \mu \mathrm{m}$. C PDD 87667 caulocystidia. D gloeoplerous stipe hyphae, in $\mathrm{NH} 4 \mathrm{OH}$ and congo red. E basidia. F lamellar trama. G PDD 87665 basidiospores, in $\mathrm{KOH}$, bar $=$ $10 \mu \mathrm{m}$. 


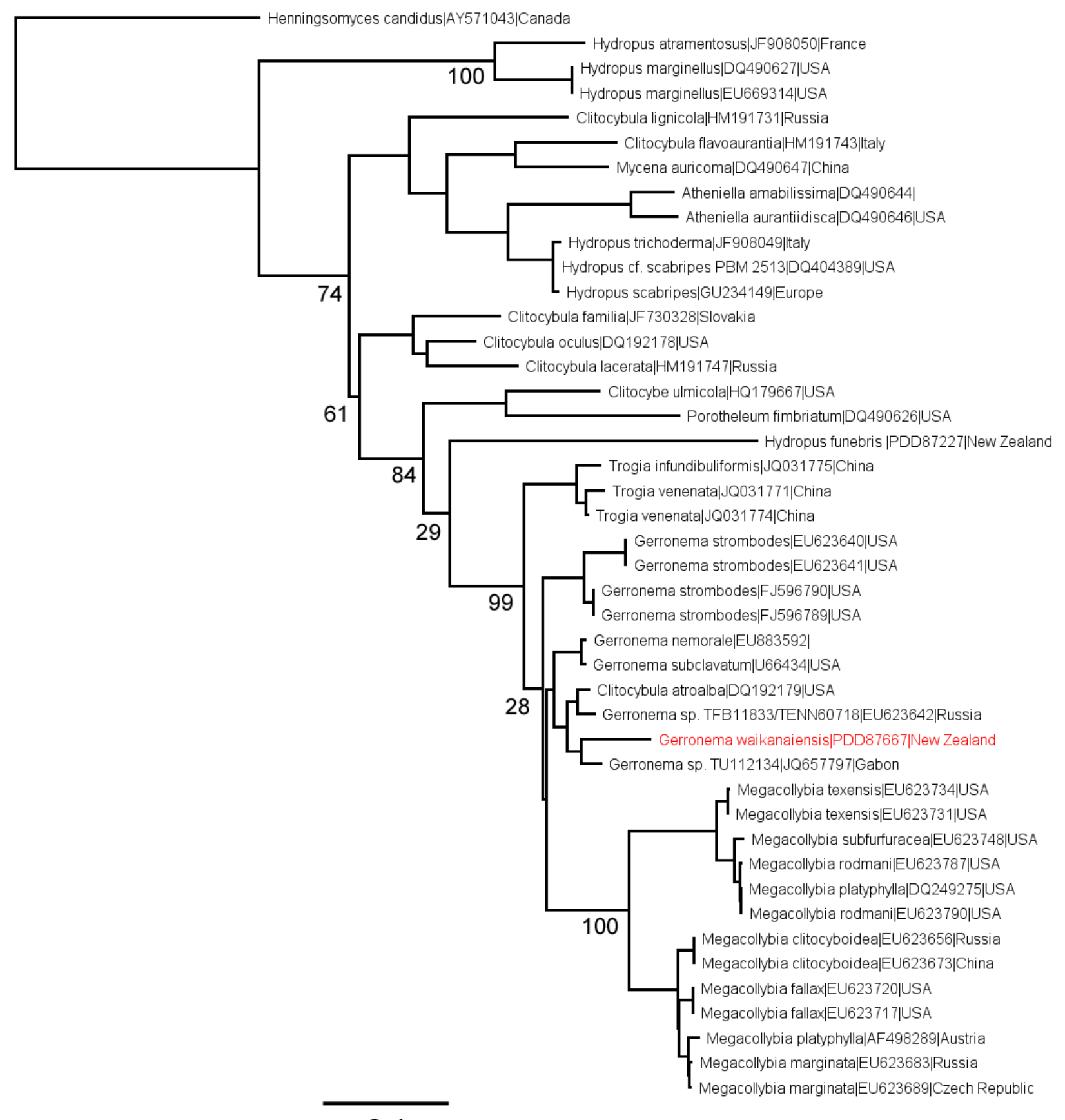

0.4

Fig. 17 - ML ITS phylogram of Gerronema waikanaensis and selected related sequences from GenBank. The tree was rooted with Henningsomyces candidus.

\section{New Taxa for New Zealand}

\section{Lyophyllum atratum (Fr.) Singer}

Figure 18

$\equiv$ Tephrocybe atrata (Fr.) Donk

Macromorphology - Pileus 10 - $20 \mathrm{~mm}$ diameter, convex, centrally depressed, brick to umber $(11 \mathrm{~F} 8-11 \mathrm{~F} 3)$ in colour, minutely fibrillose, striate towards margin. Stipe $10-20 \times 1-3$ $\mathrm{mm}$, cylindrical, hollow, concolorous with pileus. Lamellae attachment adnate, concolorous with pileus. Lamellulae present and in a series of two. Smell strong, rancid.

Micromorphology - Spore print white. Basidiospores ellipsoid, inamyloid $6.3 \pm 0.7 \times 4.5 \pm$ $0.4 \mu \mathrm{m}, \mathrm{Q}=1.4 \pm 0.1, \mathrm{n}=6$. Basidia 4-spored, $20-30 \times 7-10 \mu \mathrm{m}$, with siderophilous granules. Cystidia absent. Hyphae clamped. 
Habitat - on bonfire site with charcoal.

Known distribution and conservation status - known only from a single New Zealand collection but likely to be widespread and introduced.

Material examined - New Zealand, Mid-Canterbury, Orton Bradley Park, Diamond Harbour, on bonfire site with Eucalyptus, 10th Apr 2006, J.A. Cooper, JAC9901 (PDD 87010).

GenBank - KJ461895 (PDD 87010. LSU), KJ461896 (PDD 87010, ITS)

Notes - a number of regions (e.g. Europe, North America, Australia) possess welldocumented and characteristic indigenous communities of fungi associated with burnt sites (e.g. Adamczyk et al., 2012; McMullan-Fisher et al., 2011; Wicklow, 1975; and references therein). Current evidence based on collections in the PDD fungarium suggests this is not true in New Zealand, where the majority of fungi associated with such sites appear to be introductions, including L. atratum. Sequences of this species (Figure 6) fall within the Lyophyllum group.

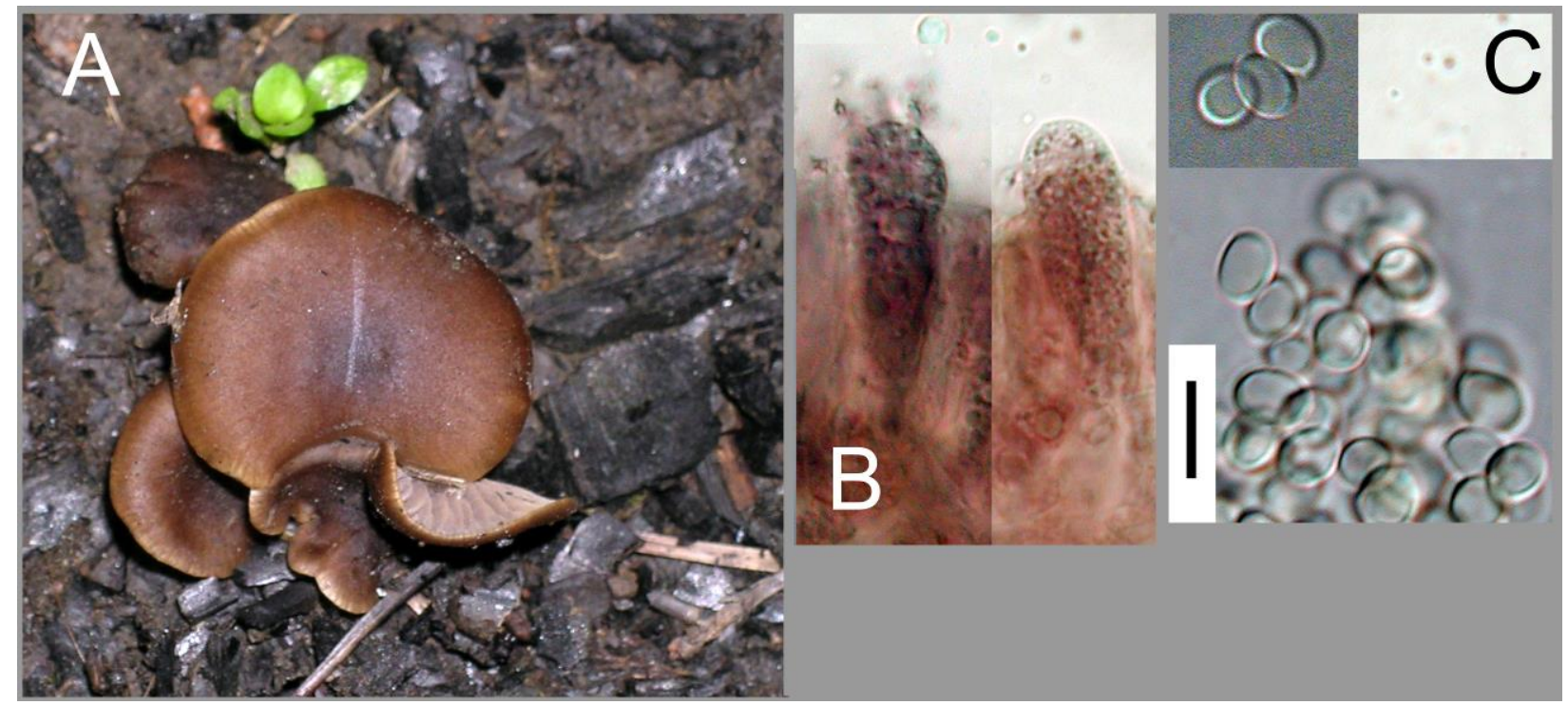

Fig. 19 - Lyophyllum atratum A PDD 87010 basidiomata. B basidia showing siderophilous granules, in acetocarmine and FeSO4. $\mathrm{C}$ basidiospores, in $\mathrm{KOH}$, bar $=10 \mu \mathrm{m}$.

\section{Acknowledgements}

Thanks to Dukchul Park, Landcare Research, for DNA extraction and sequencing, and to Pat Leonard for his collections and useful discussions concerning segregates identified in our ongoing study of Tricholoma in New Zealand. The New Zealand Department of Conservation and Christchurch City Council for permission to collect specimens from the areas they manage. Hugh Wilson \& the Maurice White Native Forest Trust for permission to collect on the Hinewai Reserve, Akaroa. The members and attendees of the Fungal Foray of New Zealand for their annual industrious collecting efforts. Teresa Lebel for useful discussions concerning Hydnangium. This work is supported through the Landcare Research Systematics Portfolio, with Core funding support from the Science and Innovation Group of the New Zealand Ministry of Business, Innovation and Employment.

\section{References}

Adamczyk JJ, Kru A, Penczak T, Minter DW. 2012 - Factors shaping communities of pyrophilous macrofungi in microhabitats destroyed by illegal campfires. Fungal Biology. 116, 9951002.

Antonin V, Ryoo R, Shin H-D. 2008 - Gerronema nemorale (Basidiomycota, Agaricomycetes): anatomic-morphological, cultivational, enzymatic and molecular characteristics and its first records in the Republic of Korea. Czech Mycol. 60, 197-212. 
Antonin V, Beran M, Borovicka J, Dvorak D, Holec J. 2011 - Clitocybula familia (Fungi, Agaricales) - taxonomy, distribution, ecology and first records in the Czech Republic and Slovakia. Czech Mycology. 63, 1-11.

Chu-Chou M, Grace LJ. 1983 - Hypogeous fungi associated with some forest trees in New Zealand. New Zeraland Journal of Botany, 21, 183-190.

Cooper JA, Leonard PL. 2012 - Boletopsis nothofagi sp. nov. associated with Nothofagus in the Southern Hemisphere. MycoKeys. 3, 13-22.

Drummond AJ, Ashton B, Buxton S, Cheung M, Cooper A, Duran C, Field M, Heled J, Kearse M, Markowitz S, Moir R, Stones-Havas S, Sturrock S, Thierer T, Wilson A. 2011 - Geneious v5.4. Available from: http://www.geneious.com/

Guindon S, Gascuel O. 2003 - A simple, fast, and accurate algorithm to estimate large phylogenies by maximum likelihood. Syst. Biol. 52, 696-704.

Hofstetter V, Clemencon H, Vilgalys R, Monclavo J-M. 2002 - Phylogenetic analyses of the Lyophylleae based on nuclear and mitochondrial rDNA sequences. Mycological Research. 106, 1043-1059.

Horak E. 1971 - A contribution towards the revision of the Agaricales (Fungi) from New Zealand. New Zealand Journal of Botany. 9, 403-462.

Horak E. 1980 - On Australasian species of Lepiota S. F. Gray (Agaricales) with spurred spores. Sydowia. 33, 111-144.

Horak E. 2008 - Agaricales of New Zealand 1: Pluteaceae \& Entolomataceae. Fungal Diversity Press, Hongkong.

Hartley AJ, de Mattos-Shipley K, Collins CM, Kilaru S, Foster GD, Bailey AM. 2009 Investigating pleuromutilin-producing Clitopilus species and related basidiomycetes. FEMS Microbiol. Letters. 297, 24-30.

Hou W, Lian B, Dong H, Jiang H, Wu X. 2012 - Distinguishing ectomycorrhizal and saprophytic fungi using carbon and nitrogen isotopic composition. Geoscience Frontiers 3, 351-356.

Hughes KW, Petersen RH, Mata JL, Psurtseva NV, Kovalenko AE, Morozova OV, Lickey EB, Blanco JC, Lewis DP, Nagasawa E, Halling RE, Takehashi S, Aime MC, Bau T, Henkel T. 2007 - Megacollybia (Agaricales). Reports of the Tottori Mycological Institute. 45, 1-57.

Hughes KW, Mather DA, Petersen RH. 2010 - A new genus to accommodate Gymnopus acervatus (Agaricales), Mycologia. 102, 1463-1478.

Johnston PR. 2010 - unpublished notes on New Zealand Type specimens held at R.B.G. Kew, available at http://nzfungi2.landcareresearch.co.nz/

Kerekes JF, Desjardin DE. 2009 - A monograph of the genera Crinipellis and Moniliophthora from Southeast Asia including a molecular phylogeny of the nrITS region. Fungal Diversity. 37, $101-152$.

Kornerup A, Wanscher JH. 1981 - Taschenlexikon der Farben. 3. Aufl.Göttingen: Muster-Schmidt Verlag.

Larsson E, Sundberg H. 2011 - Lyophyllum shimeji, a species associated with lichen pine forest in northern Fennoscandia. 1. Mycoscience 52, 289-295.

Lennox JW. 1979 - Collybioid Genera in the Pacific Northwest; Mycotaxon. 9, 117-131.

Malysheva EF, Morozova OV, Contu M. 2011 - New combinations in Clitocybula: a study of cystidiate Pseudoomphalina species (Basidiomycota, Agaricomycetes). Sydowia. 63, 85104.

Moncalvo JM, Vilgalys R, Redhead SA, Johnson JE, James TY, Aime MC, Hofstetter V, Verduin SJW, Larsson E, Baroni TJ, Thorn RG, Jacobsson S, Clémençon H, Miller OK. 2002 - One hundred and seventeen clades of euagarics. Molecular Phylogenetics and Evolution. 23, $357-400$.

Moreno G, Contu M, Ortega A, Pltas G, Pelaez F. 2007 - Molecular phylogenetic studies show Omphalina giovanellae represents a new section of Clitopilus (Agaricomycetes). Mycological Research, 111, 1399-1405. 
McMullan-Fisher SJM, May TW, Robinson RM, Bell TL, Lebel T, Catcheside P, York A. 2011 Fungi and fire in Australian ecosystems: a review of current knowledge, management implications and future directions. Australian Journal of Botany, 59, 70-90.

Readhead SA. 1987 - The Xerulaceae (Basidiomycetes), a family with sarcodimitic tissues. Can J Bot, 65, 1551-1562.

Redhead SA. 2002 - Phylogeny of agarics: partial systematics solutions for core omphalinoid genera in the agarciales (euagarics). Mycotaxon, 83, 19-57.

Redhead SA, Hofstetter V, Clemencon H, Vilgalys R, Monclavo J-M. 2006 - (1742) Proposal to conserve the name Lyophyllum with a conserved type (Basidiomycota). Taxon 55, 1034 1036.

Robbich G. 2003 - Mycena D'Europa. Associazione Micologica Bresadola.

Singer R. 1986 - The Agaricales in Modern Taxonomy. 4th ed. - Koeltz Scientific Books, Koenigstein.

Species Fungorum. 2013- http://www.speciesfungorum.org

Watling R, Gregory NM. 1989 - British Fungus Flora. V6/ Crepidotaceae, Pleurotaceae and other pleurotoid agarics. R.B.G.E.

Wicklow DT. 1975 - Fire as an environmental cue initiating ascomycete development in a tallgrass prairie. Mycologia. 67, 852-862.

Yang ZL, Li YC, Tang LP, Shi GQ, Zeng G. 2012 - Trogia venenata (Agaricales), a novel poisonous species which has caused hundreds of deaths in southwestern China. Mycological Progress, 11, 937-945. 